Research Article

\title{
Effects of Pore Structure on Sandstone Mechanical Properties Based on Micro-CT Reconstruction Model
}

\author{
Rui Song $\mathbb{D},{ }^{1,2}$ Lifu Zheng $\mathbb{D}^{1},{ }^{1}$ Yao Wang $\mathbb{D}^{1},{ }^{1}$ and Jianjun Liu $\mathbb{D}^{2}$ \\ ${ }^{1}$ School of Geoscience and Technology, Southwest Petroleum University, Chengdu 610500, China \\ ${ }^{2}$ State Key Laboratory of Geomechanics and Geotechnical Engineering, Wuhan Institute of Rock and Soil Mechanics, \\ Chinese Academy of Sciences, Wuhan 430071, China
}

Correspondence should be addressed to Lifu Zheng; lifuzheng@stu.swpu.edu.cn

Received 7 August 2019; Revised 1 January 2020; Accepted 28 January 2020; Published 24 February 2020

Academic Editor: Dong Zhao

Copyright (c) 2020 Rui Song et al. This is an open access article distributed under the Creative Commons Attribution License, which permits unrestricted use, distribution, and reproduction in any medium, provided the original work is properly cited.

\begin{abstract}
As porous, heterogeneous, and anisotropic material, the microscopic structure of the rock has a significant influence on its mechanical properties. Rare studies were devoted to this area using pore scale modeling and simulations. In this paper, different types of sandstones are imaged using micro-CT technology. The rock porosity is obtained by filtering, binarization, and threshold segmentation. The texture coefficient (TC) and the tortuosity of the rock skeleton are calculated by open source program, where the tortuosity of the rock skeleton is firstly used to characterize the microscopic structure of the rock. Combining with the rock mechanics parameters obtained in the laboratory, the simulation of uniaxial compression is performed on the reconstructed pore scale rock finite element mesh model by ANSYS software. Young's modulus, compressive strength, yield strength, shear modulus, and other related parameters obtained by numerical simulation are adopted to determine the optimal representative volume element (RVE) size. Moreover, the effects of microscopic structure characteristics on the mechanical properties of the rock are studied quantitatively. The results indicate that the averaged von Mises stress distribution, displacement field, and plastic strain field of rocks show anisotropy and heterogeneity. The stress concentration and the X-shaped conjugate plastic shear zone are investigated. The samples of S1 S4 reach the elastic limit and enters the plastic yield state, when the strain is about $0.5 \%$. And the critical yield strain of samples $S 5_{300-1} \sim S 5_{400-2}$ is about $1 \%$. Then, the quantitative relationships between porosity, TC, tortuosity of rock skeleton and rock mechanics parameters of digital rock samples are established and analyzed. The tortuosity of the rock skeleton is highly correlated with the mechanical parameters of the rock, i.e., Young's modulus $\left(R^{2}=0.95\right)$, compressive strength $\left(R^{2}=0.94\right)$, yield strength $\left(R^{2}=0.92\right)$, and shear modulus $\left(R^{2}=0.94\right)$, which is believed to be more feasible to reveal the impacts of the microstructure of the rock on its mechanical properties.
\end{abstract}

\section{Introduction}

Rock is a natural porous media with anisotropy, heterogeneity, and discontinuity, which is related to many engineering applications, e.g., resource exploitation, civil construction, and tunnel excavation $[1,2]$. The microstructure of the rock has been regarded as one of the important factors for the formation of shear zone, stress concentration, and cracking, which will threaten the safety of geotechnical engineering. Consequently, it is of practical significance to investigate the effects of the rock microstructure on its mechanical properties [3].

For the nontransparent rock with disorder and complex pore structure, the nondestructive and high-resolution CT technology has been used to acquire the 3D structure of the rock. The internal microstructure of the rock is quantitatively analyzed by the microscopic CT image [4-6]. In addition, the CT technology was also used to image the evolution of the rock microstructure under different loads. Argandoña et al. [7] studied the heterogeneity of the rock structure and pore distribution using the established $3 \mathrm{D}$ rock model by CT image processing and analyzed the evolution of the pore structure in the freezing-thawing cycles. Kawakata et al. [8] used the method to analyze the deformation and fracture modes of granite under uniaxial and triaxial conditions. Ge et al. [9] studied the microfracture process of the rock by using CT scanning technology and analyzed the 
deformation of micropores and microcracks under different stress conditions. Ueta et al. [10] investigated the shear bands in sandstones combing CT scanning and shear experiments. Bésuelle et al. [11] used the technology to analyze the strain localization characteristics and the evolution process of the clay rock under triaxial compression. Wang et al. [12] investigated the relationship between various damage parameters (e.g., crack spacing and area) and mechanical properties of concrete materials. Tian et al. [13] identified and extracted cracks from the micro-CT images of concrete and acquired the length, width, and area of cracks by using statistical principles to characterize the microcosmic damage and fracture mechanism of concrete. Li et al. [14] also used the technology to study the mechanical properties of sandstone soaked in acid solution and quantitatively analyzed the damage degree of sandstone.

Furthermore, many scientific efforts have been made to reveal the relationships between the parameters acquired from the microscale images (e.g., porosity) and mechanical properties of the rock. Fjar et al. [15] used quantitative and qualitative methods to analyze the relationships between the rock microstructure and its mechanical properties. AlHarthi et al. [16] found the uniaxial compressive strength and Young's modulus of the Basalt and Tuff gradually decreased with the increase of porosity. Li and Wang [17] studied the effects of porosity on the mechanical properties and energy dissipation of dry and saturated porous sandstones by SHPB experiments. The results show that the strength of dry sandstone decreases and the energy dissipation increases with the increase of porosity. Howarth and Rowlands [18] firstly proposed the concept of texture coefficient (TC) to characterize the complexity of grains and put up with the mathematical expression. The TC of sandstone, igneous, and marble samples were calculated by electron microscope slices $(10 \mathrm{~mm} \times 10 \mathrm{~mm})$, and a good correlation between TC and the mechanical properties were obtained. Ersoy and Waller [19] obtained the TC value of the artificial sandstone flakes $(30 \mathrm{~mm} \times 50 \mathrm{~mm})$ and conducted the polycrystalline diamond tablet drilling tests. The results indicate the TC can be used to evaluate rock drillability, mechanical properties, and wear-resisting performance. Azzoni et al. [20] obtained the texture coefficients of several different lithologies, such as igneous rock, metamorphic rock, and sedimentary rock $(80 \mathrm{~mm} \times 160 \mathrm{~mm})$, and found close connections between TC and compressive properties of granite, sandstone, and marble. Although the correlation between gneiss and rhyolite is not obvious, TC can be used as a tool to describe and classify different lithologies. Alber and Kahraman [21] obtained the compressive strength of the rock sample and the TC of the fault breccia slices $(d=7.6 \mathrm{~mm}-73 \mathrm{~mm})$. They found the compressive strength decreases with the increase of TC $\left(R^{2}=0.83\right)$ when $0<\mathrm{TC}<0.9$, and the modulus of elasticity decreases as TC increases when $0.25<\mathrm{TC}<0.5$. Tandon and Gupta [22] studied the properties of different rocks in the Himalayas and calculated the texture coefficients of minerals, such as mica, feldspar, tourmaline, hornblende, pyroxene, and dolomite. They found the compressive strength increases with the increase of TC $\left(R^{2}=0.81\right)$ when $1.5<\mathrm{TC}<3.5$. Ozturk and Nasuf [23] calculated the TC values of rocks by using SEM images of samples $(9 \mathrm{~mm} \times 9 \mathrm{~mm})$ and studied the relationship between $\mathrm{TC}$ and the uniaxial compressive strength of rocks.

Scholars carried out the simulations on the reconstructed mesh model to study the mechanical properties of the rock by using micro-CT images. Chen et al. [24] reconstructed the three-dimensional rock model by using the two-dimensional rock image and studied the mechanical response and failure process under conventional Brazilian tensile test conditions by using FLAC3D. Zhu et al. [25] obtained the mineral compositions and extracted the pore distributions of rock by CT technology and simulated the cracking of the reconstructed rock model in the fluid-solid coupling process by RFPA. Yang et al. [26] and Zhu et al. [27] also used RFPA to simulate the deformation and fracture process of reconstructed rock models in uniaxial compression and Brazil disk test, respectively, and studied the impact of voids and fractures on the rock failure mode. Ju et al. [28] combined the CT imaging and X-ray diffraction with physical tests to obtain the pore structure, mineral composition, and mechanical properties of sandstone and established three-dimensional finite element mesh models with different porosity by using Mimics software. The pore scale deformation failure mechanism and energy dissipation of rock were investigated under stress wave propagation by numerical simulation. Tian et al. [29] and Wang [30] used the same modeling methods to simulate the uniaxial compressive and tensile properties of concrete and rock, respectively. Song et al. [31,32] and Wang et al. [33] adopted rock microscopic CT imaging and structured the finite element mesh model reconstruction method to establish the finite element model in microscale for sandstone skeleton and pore, and the evolution of pore structure and permeability of the rock was carried out by numerical simulation. Wang [34] reconstructed rock microstructure models from CT images by using MATLAB software and analyzed the evolution process of rock failure by FLAC3D. Cheng et al. [35] conducted uniaxial compression simulations on the two-dimensional reconstructed rock models and found that the effective elasticity modulus decreases exponentially with the increase of porosity. Liu et al. [36] established threedimensional finite element mesh models of synthetic sandstone rock samples and conducted the numerical simulation of uniaxial compression. The cohesive force and internal friction angle decrease linearly with the increase of porosity when the porosity is between $8 \%$ and $28 \%$.

In this paper, microscopic images of different types of sandstone samples are obtained by CT scanning technology. Combining with image processing, the porosity of rock samples is obtained. Open source programs are used to calculate the TC and tortuosity of the rock skeleton. The finite element mesh models with different porosities are reconstructed by model reconstruction algorithm. Based on the mechanical parameters of core scale, ANSYS software is used to carry out the numerical simulation of uniaxial compression. The calculated mechanical parameters (e.g., Young's modulus, the compressive strength, and the yield strength) and microstructure parameters (e.g., TC and the 
tortuosity) of the rock are used to determine the optimal RVE. Moreover, the averaged von Mises stress distribution, displacement field, and plastic strain field of the rock are analyzed qualitatively. In addition, the relationship between the porosity, TC and the tortuosity of the rock skeleton, and mechanical parameters are used to quantitatively characterize mechanical properties of the rock.

\section{Mathematical Model}

2.1. Plasticity Criterion. Considering the influence of the microstructure on rock mechanical strength, the von Mises yield criterion has been widely applied in the microscale deformation-fracture process of the rock, which are adopted for determining the plastic deformation of the rock skeleton [37-39].

The criterion states that yielding begins when the elastic energy of distortion reaches a critical value [40]. That is, when the second invariant of the stress deviator $\left(J_{2}^{\prime}\right)$ reaches a critical value, it represents plastic status, which can be expressed as follows:

$$
f\left(\sigma_{i j}^{\prime}\right)=J_{2}^{\prime}=C,
$$

where $J_{2}{ }^{\prime}$ is the second invariant of the stress tensor and $C$ is a constant related to material property and independent of the stress state, which can be measured experimentally.

The second invariant of the stress tensor is as follows:

$$
J_{2}^{\prime}=\frac{1}{6}\left[\left(\sigma_{x}-\sigma_{y}\right)^{2}+\left(\sigma_{y}-\sigma_{x}\right)^{2}+\left(\sigma_{z}-\sigma_{x}\right)^{2}+6\left(\tau_{x y}^{2}+\tau_{y z}^{2}+\tau_{z x}^{2}\right)\right]=C,
$$

where $\sigma_{x}, \sigma_{y}$, and $\sigma_{z}$ are normal stresses in different directions $(\mathrm{Pa})$ and $\tau_{x y}, \tau_{x z}$, and $\tau_{y z}$ are shear stresses $(\mathrm{Pa})$.

Equation (2) can be defined as effective stress as follows:

$$
\bar{\sigma}=\sqrt{\frac{1}{2}\left[\left(\sigma_{1}-\sigma_{2}\right)^{2}+\left(\sigma_{2}-\sigma_{3}\right)^{2}+\left(\sigma_{3}-\sigma_{1}\right)^{2}\right]}=\sqrt{3 C},
$$

where $\bar{\sigma}$ is effective stress $(\mathrm{Pa})$ and $\sigma_{1}$ and $\sigma_{3}$ are principal stresses $(\mathrm{Pa})$.

Thus, the Mises yield condition can be represented by more convenient effective stress. It can be expressed as equation (4) in the form of the principal stress and simplified as shown in the following equation:

$$
\begin{aligned}
& J_{2}^{\prime}=\frac{1}{6}\left[\left(\sigma_{1}-\sigma_{2}\right)^{2}+\left(\sigma_{2}-\sigma_{3}\right)^{2}+\left(\sigma_{3}-\sigma_{1}\right)^{2}\right]=C, \\
& \bar{\sigma}=\sqrt{3 J_{2}^{\prime}}=\sqrt{3 C} .
\end{aligned}
$$

2.2. Multilinear Kinematic Hardening. The stress-strain curve of sandstone samples is obtained by laboratory experiments, as shown in Figure 1. The samples S1-S2 are drilled from the same origin core sample with the size of $5 \mathrm{~cm} \times \Phi 2.5 \mathrm{~cm}$, so it is with the sample S3-S4. The subscript of sample S5 means the cubic voxel with different subscript are extracted from the micro-CT image and used for RVE

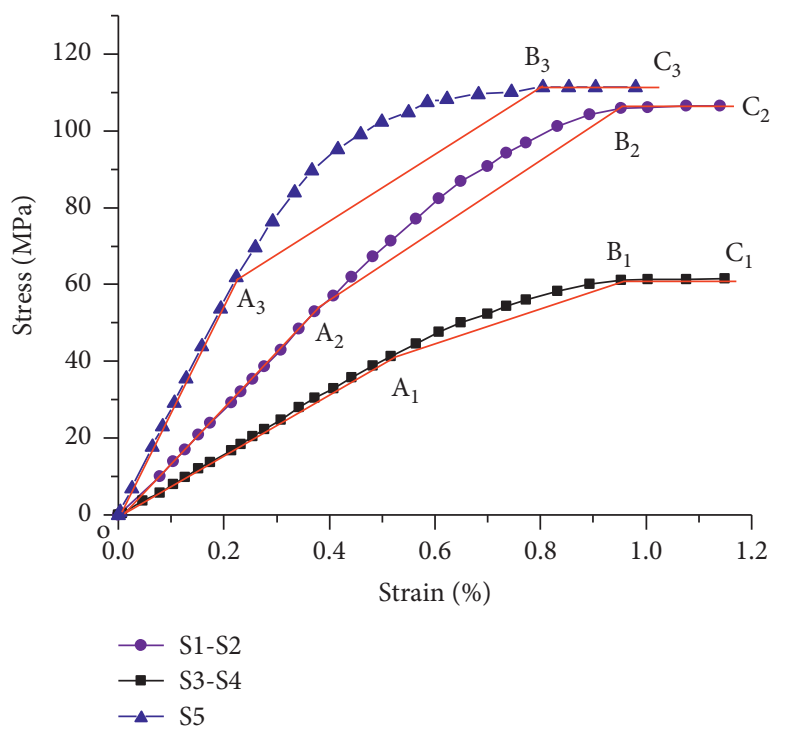

FIGURe 1: Multilinear kinematic hardening.

analysis. According to the determination of tangential modulus proposed by Fairhurst and Hudson [41], 50\% of the uniaxial compressive strength of the rock is selected as the yield point, and the tangential modulus is defined as the slope of the curve between the yield point and the compressive strength point.

As shown in Figure 1, points $A_{1}, A_{2}$, and $A_{3}$ are the yield points and $B_{1}, B_{2}$, and $B_{3}$ are the compressive limits. It should be stated that the mechanical parameters used in this paper are core scale test results. Considering the effect of the pore structure characteristics on the rock mechanical properties, the results are based on the model values/input values to reduce the scale effect of the input parameters on the results. The parameters used in the numerical simulation are shown in Table 1 . These input mechanical parameters are calculated by the stress-strain curve (Figure 1) of the uniaxial compression test at the core scale. As stated by Liu and Tang [42], Young's modulus is the slope of the elastic deformation stage $\left(\mathrm{OA}_{1}, \mathrm{OA}_{2}\right.$, and $\mathrm{OA}_{3}$ ) and the compressive strength is the value of points $\mathrm{B}_{1}, \mathrm{~B}_{2}$, and $\mathrm{B}_{3}$. The volume modulus and shear modulus are obtained according to equations (6) and (7), respectively:

$$
\begin{gathered}
G=\frac{E}{2(1+v)}, \\
K_{v}=\frac{E}{3(1-2 v)},
\end{gathered}
$$

where $E$ is Young's modulus (GPa), $G$ is shear modulus (GPa), $v$ is Poisson's ratio, and $K_{V}$ is volume modulus (GPa).

The four-linear model proposed by $\mathrm{Lu}[43]$ is adopted in the study, which describes the bilinear elasticity, linear softening, and residual ideal plasticity model of the rock. As shown in Figure 1, the red line $\mathrm{OA}_{1}, \mathrm{OA}_{2}$, and $\mathrm{OA}_{3}$ are linear elastic deformation stages. The rock changes from elastic deformation into plastic deformation after the yield points $A_{1}$, $A_{2}$, and $A_{3}$, which behaves as nonlinear deformation. For the convenience of analysis and application, it is simplified into 
TABLE 1: Input parameters of numerical simulation.

\begin{tabular}{lcccccc}
\hline Model & $\begin{array}{c}\text { Young's modulus } \\
(\mathrm{GPa})\end{array}$ & $\begin{array}{c}\text { Compressive strength } \\
(\mathrm{MPa})\end{array}$ & $\begin{array}{c}\text { Yield strength } \\
(\mathrm{MPa})\end{array}$ & $\begin{array}{c}\text { Poisson's } \\
\text { ratio }\end{array}$ & $\begin{array}{c}\text { Bulk Modulus } \\
(\mathrm{GPa})\end{array}$ & $\begin{array}{c}\text { Shear modulus } \\
(\mathrm{GPa})\end{array}$ \\
\hline S5 $5_{100-1}$ & & & & & & \\
S5 ${ }_{400-2}$ & 27.83 & 112.11 & 61.97 & 0.296 & 22.737 & 10.737 \\
& & & & & & \\
S1-S2 & 13.864 & 105.94 & 52.93 & 0.296 & 11.327 & 53.488 \\
S3-S4 & 7.803 & 61.4 & 44.5 & 0.296 & 6.375 & 3.01 \\
\hline
\end{tabular}

the linear hardening stage. After points $\mathrm{B}_{1}, \mathrm{~B}_{2}$, and $\mathrm{B}_{3}$, plastic failure occurs in rocks. $\mathrm{B}_{1} \mathrm{C}_{1}, \mathrm{~B}_{2} \mathrm{C}_{2}$, and $\mathrm{B}_{3} \mathrm{C}_{3}$ are simplified to the ideal plastic stage. At this stage, the compressive strength of the rock will not change with the variation of strain.

\section{Digital Core RVE Analysis}

3.1. Digital Core Model. In this paper, micro-CT images are obtained by micro-CT scanning. After filtering, threshold segmentation, and converting into digital images, the finite element mesh model of the rock pore scale skeleton is reconstructed. 16 models with different porosity are obtained. S1 is taken as an example, as shown in Figure 2.

3.2. Characterized Parameters of Rock Microstructure. The porosity, TC, and tortuosity of the rock skeleton are used as the characterized parameters of the rock microstructure in this paper.

3.2.1. Texture Coefficient. Texture coefficient is a dimensionless parameter, which is used to quantitatively describe the shape, orientation, interlocking degree, and relative properties of grain and matrix [18]. The texture factor takes into account the contour (or grain shape) of the grain, the degree of orientation, and interlocking and the area, length, width, etc. of the grain by image analysis on the thin section of the rock, which can be expressed as follows:

$$
\mathrm{TC}=\mathrm{AW}\left[\left(\frac{N_{0}}{N_{0}+N_{1}} \times \frac{1}{\mathrm{FF}_{0}}\right)+\left(\frac{N_{1}}{N_{0}+N_{1}} \times \mathrm{AR}_{1} \times \mathrm{AF}_{1}\right)\right],
$$

where TC is the texture coefficient; AW is grain area weighting; $N_{0}$ and $N_{1}$ represent the number of grain with aspect ratio less than 2 and greater than 2 , respectively; $\mathrm{FF}_{0}$ is the arithmetic mean of shape factor of $N_{0}$ grains, and the formula for each grain shape factor is $\left(4 \pi S / L^{2}\right), S$ is the area of grains and $L$ is the perimeter of the grains; $A R_{1}$ is the arithmetic mean of aspect ratio of $N_{1}$ grains; $\mathrm{AF}_{1}$ is angle factor orientation of $N_{1}$ grains, its calculation formula is

$$
\mathrm{AF}_{1}=\frac{1}{5} \sum_{i=1}^{9} \frac{X_{i}}{(N(N-1) / 2)},
$$

where $N$ is the number of elongated grains, $X_{i}$ is the number of angular differences in each class, and $i$ is the weighting factor and class number.

The pores are regarded as grains with the mechanical strength of 0 . The images of $X, Y$, and $Z$ directions are

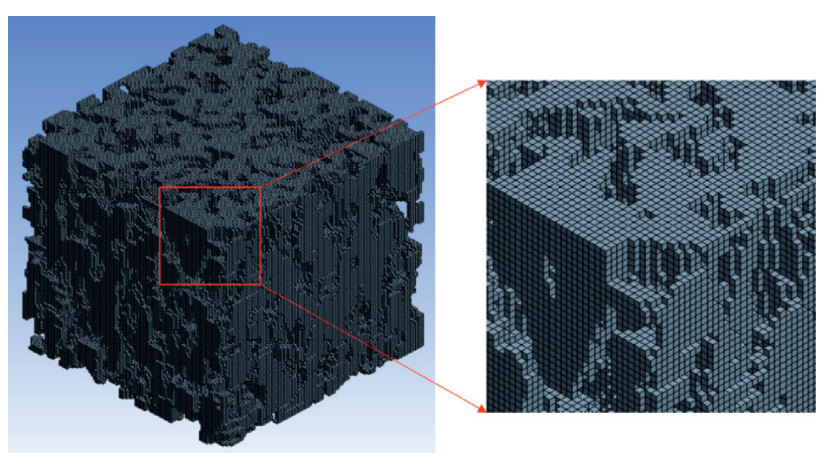

Figure 2: Rock skeleton finite element mesh model.

generated by the VRML of AVIZO software. The pore-related parameters of each section are calculated using the ImageJ software [22], such as area, perimeter, length, width, and alignment direction, as shown in Figure 3. The relevant sizes of the two-dimensional section are shown in Table 2. Moreover, the average TC of all slices of each model are calculated, as shown in Table 3. The TC values of the same sample vary with the different directions, indicating the anisotropy of this microstructure parameter.

3.2.2. Tortuosity of Rock Skeleton. The tortuosity is defined as the ratio of the actual length of the percolation channel to the apparent length (macroscopic distance) through the percolation medium, as shown in Figure 4. The tortuosity firstly proposed by Epstein [44] was used to describe the seepage channel. It can be described as

$$
\tau=\frac{L_{t}}{L_{0}},
$$

where $L_{t}$ is the length of the curved line $(\mathrm{mm})$ and $L_{0}$ is the length of the straight line of the medium $(\mathrm{mm})$.

However, the curved line $L_{t}$ is difficult to calculate directly. Thus, the TauFactor codes programmed by Cooper et al. [45] using MATLAB software are adopted to calculate the tortuosity factor. The codes simulate the reduction in diffusive transport caused by convolution in the geometry of heterogeneous media using the voxels directly as mesh elements, which can be expressed as follows:

$$
D^{\text {eff }}=D \frac{\varepsilon}{\tau},
$$

where $\varepsilon$ is the volume fraction of the conductive phase; $D$ is the intrinsic diffusivity of the conductive phase; $D^{\text {eff }}$ is the effective diffusivity through a porous volume; and $\tau$ is the 


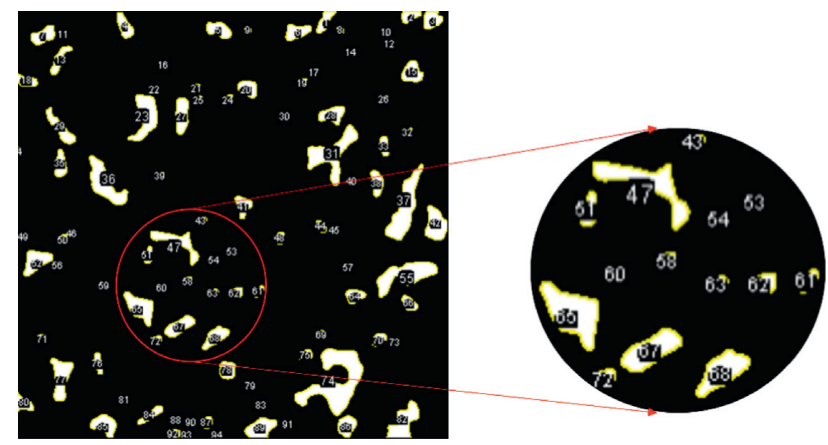

FIgURE 3: Schematic diagram of solution of pore TC.

TABLE 2: Size of all slices.

\begin{tabular}{lclc}
\hline Model & Model size $(\mathrm{mm})$ & Model & Model size $(\mathrm{mm})$ \\
\hline S1 & $1.3 \times 1.3$ & $\mathrm{~S}_{200-2}$ & $0.42 \times 0.42$ \\
S2 & $1 \times 1$ & $\mathrm{S5}_{200-1}$ & $0.42 \times 0.42$ \\
S3 & $0.75 \times 0.75$ & $\mathrm{S5}_{250-1}$ & $0.53 \times 0.53$ \\
S4 & $1 \times 1$ & $\mathrm{~S}_{250-2}$ & $0.53 \times 0.53$ \\
S5 $_{100-1}$ & $0.21 \times 0.21$ & $\mathrm{S5}_{300-1}$ & $0.63 \times 0.63$ \\
S5 $_{100-2}$ & $0.21 \times 0.21$ & $\mathrm{S5}_{300-2}$ & $0.63 \times 0.63$ \\
S5 $_{150-1}$ & $0.32 \times 0.32$ & $\mathrm{~S}_{400-1}$ & $0.84 \times 0.84$ \\
S5 $_{150-2}$ & $0.32 \times 0.32$ & $\mathrm{~S} 5_{400-2}$ & $0.84 \times 0.84$ \\
\hline
\end{tabular}

TABle 3: Average TC values of the model.

\begin{tabular}{lccc}
\hline Model & \multicolumn{3}{c}{ Direction } \\
& $X$ & $Y$ & $Z$ \\
\hline S1 & 0.124 & 0.132 & 0.197 \\
S2 & 0.133 & 0.163 & 0.164 \\
S3 & 0.48 & 0.46 & 0.599 \\
S4 & 0.482 & 0.47 & 0.396 \\
S5 $5_{100-1}$ & 0.151 & 0.191 & 0.187 \\
S5 $_{100-2}$ & 0.146 & 0.153 & 0.142 \\
S5 $_{150-1}$ & 0.069 & 0.06 & 0.161 \\
S5 $_{150-2}$ & 0.058 & 0.045 & 0.176 \\
S5 $_{200-1}$ & 0.132 & 0.095 & 0.122 \\
S5 $_{200-2}$ & 0.127 & 0.123 & 0.163 \\
S5 $_{250-1}$ & 0.098 & 0.089 & 0.102 \\
S5 $_{250-2}$ & 0.103 & 0.105 & 0.119 \\
S5 $_{300-1}$ & 0.093 & 0.086 & 0.100 \\
S5 $_{300-2}$ & 0.094 & 0.091 & 0.109 \\
S5 $_{400-1}$ & 0.097 & 0.083 & 0.095 \\
S5 $_{400-2}$ & 0.089 & 0.089 & 0.105 \\
\hline
\end{tabular}

tortuosity factor. The codes are based on the theory of pixelincorporated array convolution and Dirichlet boundary of digital rock images.

The tortuosity is usually used to describe the bending ratio of a fluid through a rock pore channel. Here, the tortuosity of the rock skeleton is adopted and calculated to quantitatively describe the microstructure of the rock matrix. Based on the acquired microscopic image data, the tortuosity in different directions is obtained, then the skeleton tortuosity of 16 kinds of microscopic images is calculated, as shown in Table 4. The tortuosity values of the same sample vary from the different directions, indicating the anisotropy of microstructure parameter of the rock matrix.

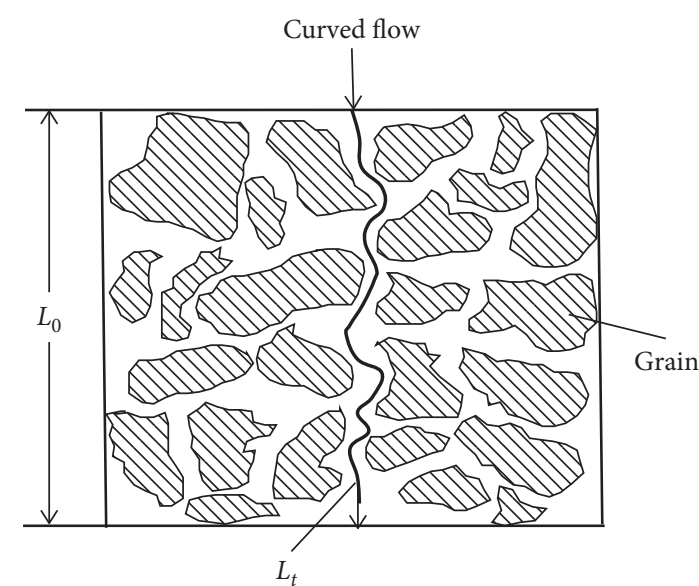

FIgURE 4: Schematic diagram of fluid passing through a porous medium.

TABle 4: Model's tortuosity parameters.

\begin{tabular}{lccc}
\hline Model & \multicolumn{3}{c}{ Direction } \\
& $X$ & $Y$ & $Z$ \\
\hline S1 & 1.22 & 1.2 & 1.28 \\
S2 & 1.09 & 1.53 & 1.59 \\
S3 & 2.2 & 2.36 & 2.9 \\
S4 & 2.02 & 2.22 & 1.83 \\
S5 $5_{100-1}$ & 1.14 & 1.13 & 1.15 \\
S5 $_{100-2}$ & 1.13 & 1.4 & 1.14 \\
$\mathrm{~S}_{150-1}$ & 1.1 & 1.12 & 1.16 \\
$\mathrm{~S}_{150-2}$ & 1.15 & 1.12 & 1.15 \\
$\mathrm{~S}_{200-1}$ & 1.13 & 1.13 & 1.15 \\
$\mathrm{~S}_{200-2}$ & 1.12 & 1.15 & 1.16 \\
$\mathrm{~S}_{250-1}$ & 1.12 & 1.12 & 1.14 \\
$\mathrm{~S}_{250-2}$ & 1.14 & 1.14 & 1.15 \\
$\mathrm{~S}_{300-1}$ & 1.12 & 1.12 & 1.14 \\
$\mathrm{~S}_{300-2}$ & 1.14 & 1.14 & 1.15 \\
$\mathrm{~S}_{400-1}$ & 1.12 & 1.12 & 1.14 \\
$\mathrm{~S}_{400-2}$ & 1.14 & 1.14 & 1.15 \\
\hline
\end{tabular}

3.3. RVE Analysis of the Digital Rock Models. The RVE is the smallest subvolume of the heterogeneous material to be used to determine the corresponding effective properties for the macroscopic model. The RVE should be large enough to contain sufficient information about the microstructure in order to be representative; however, it should be much smaller than the macroscopic body [46]. RVE is considered the basic concept for estimating average or overall properties of heterogeneous solids. It can not only represent the effective response of the microstructure but also minimize the computational effort. As shown in Figure 5(a), a cubic of $100-400$ pixels is extracted from the center of the original three-dimensional cylindrical rock sample image, which is gradually expanded to the surrounding area. The microscale deformation analysis of the digital core requires an accurate physical model, which can represent the microstructure of the core and meet the needs of computer simulation.

The displacement loading is used to simulate the pore scale uniaxial compression in the $X, Y$, and $Z$ directions. The 


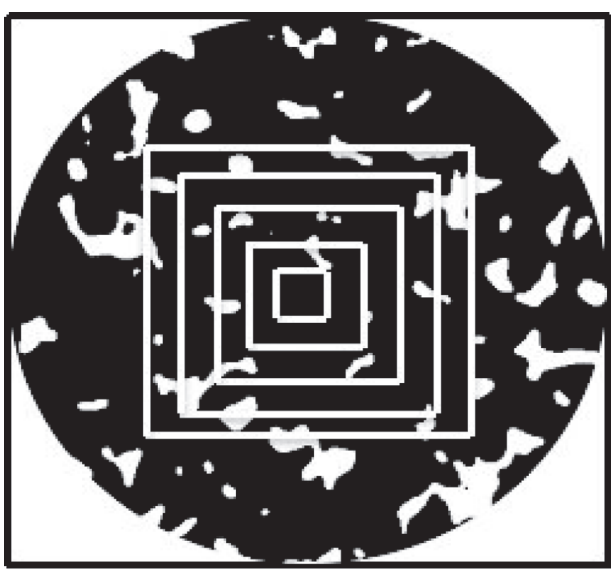

(a)

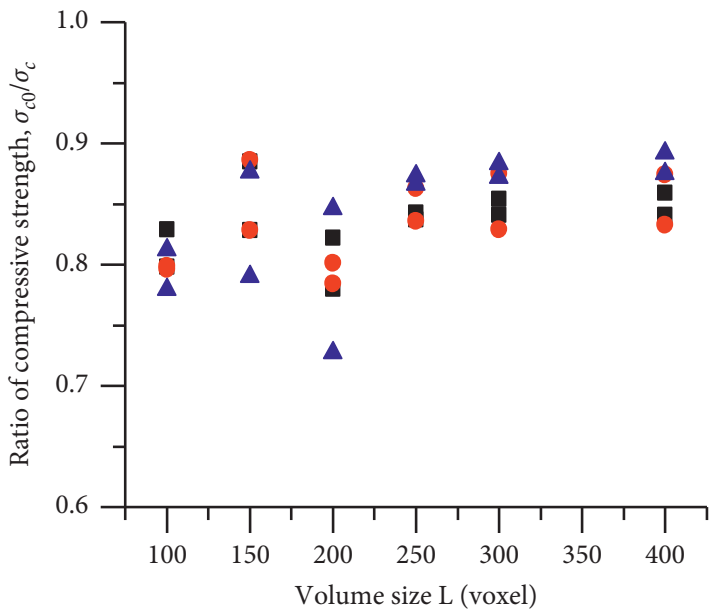

- $X$

- $Y$

- $Z$

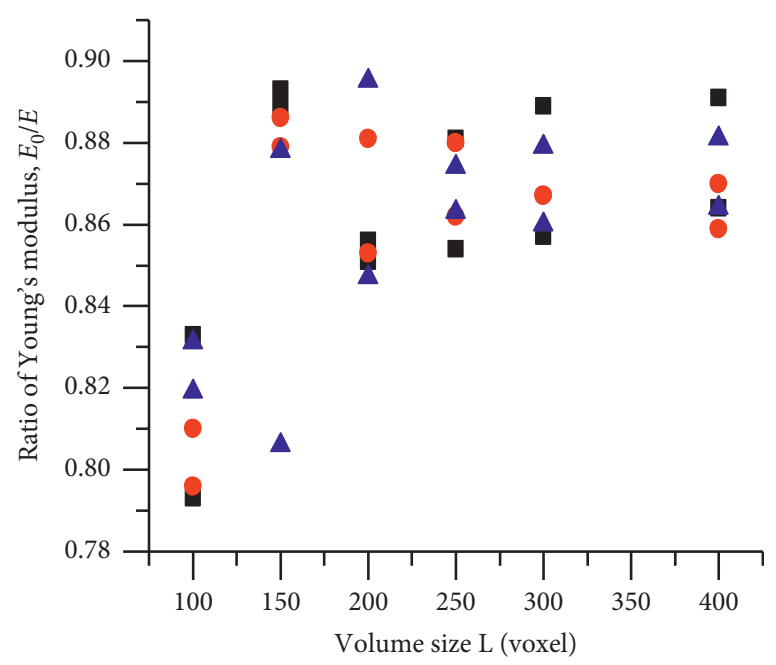

- $X$

$\Delta Z$

(b)

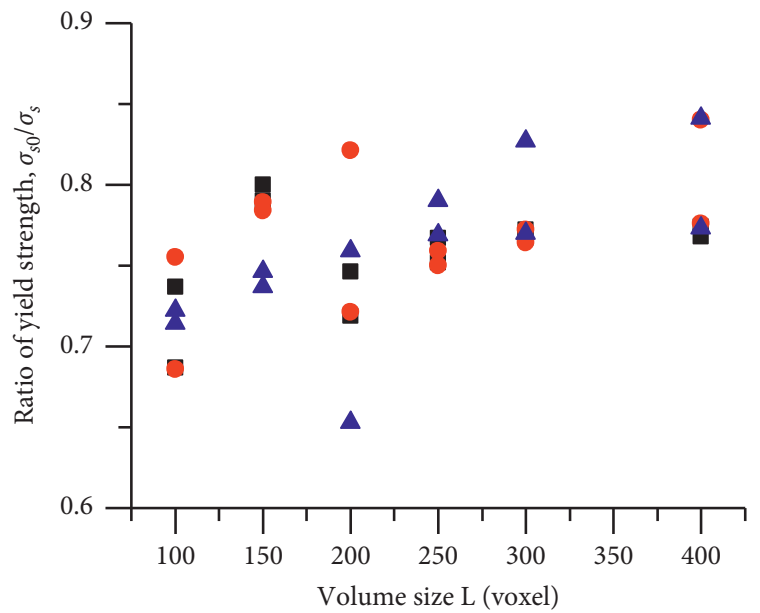

- $X$

- $Y$

$\Delta Z$

(c)

(d)

FIgURE 5: Continued. 

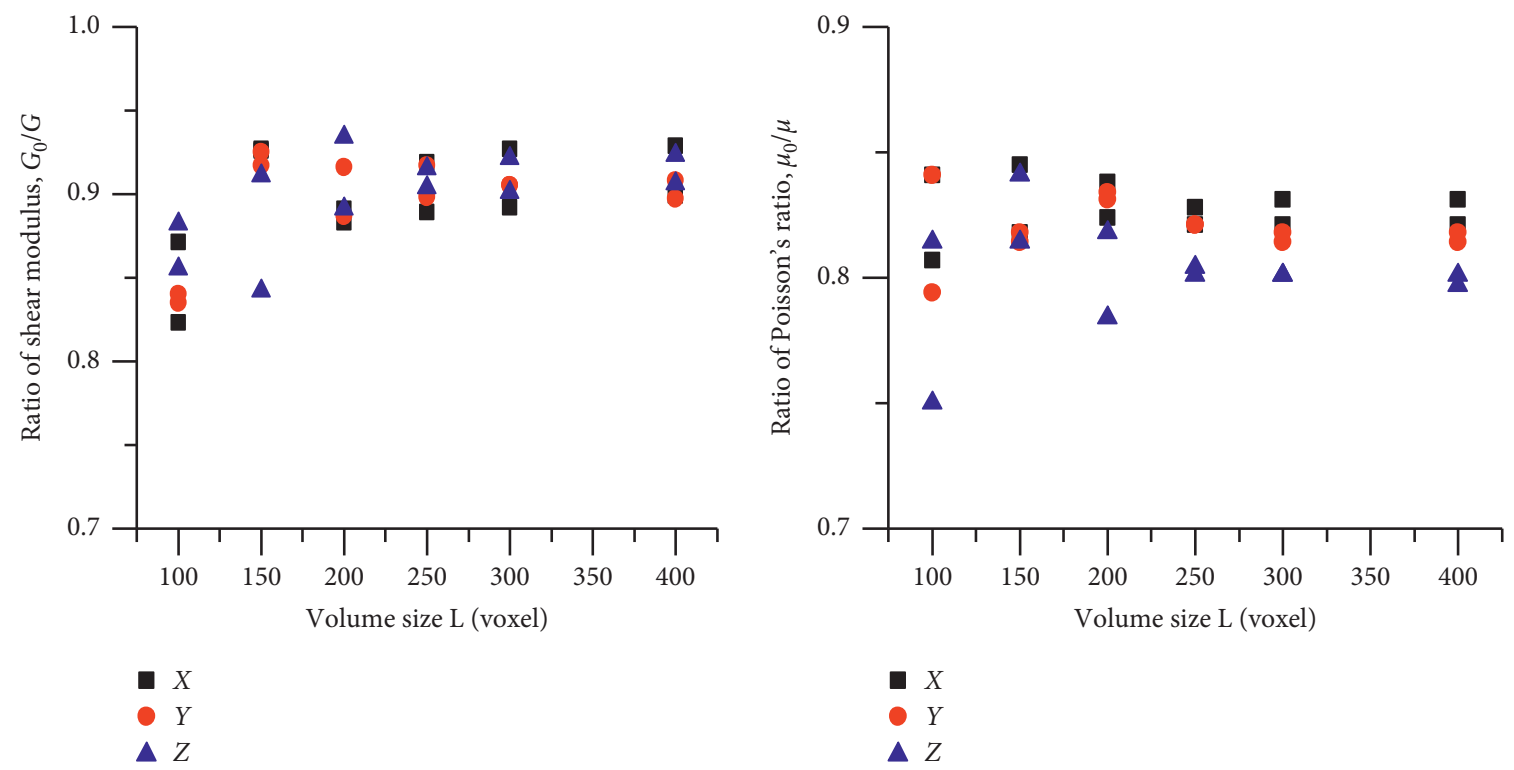

(e)

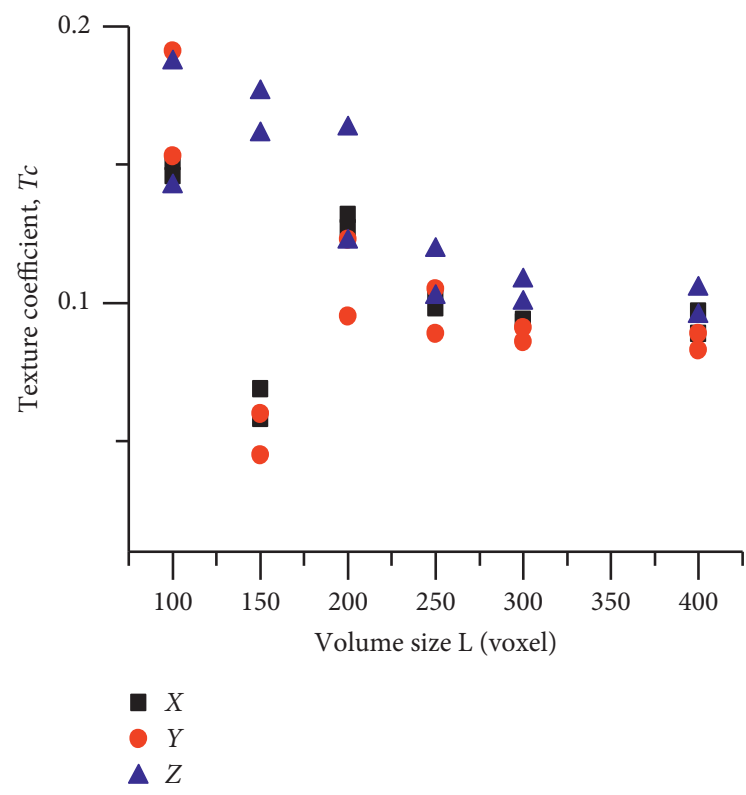

(g)

(h)

FIGURE 5: RVE analysis of mechanical properties and microstructure: (a) the model selection for RVE analysis and (b) (h) the ratio of Young's modulus, ratio of compressive strength, ratio of yield strength, ratio of shear modulus, ratio of Poisson's ratio, tortuosity, and TC against the model size for the RVE analysis.

fixed constraint is set at the bottom of the model, and the top is the displacement loading condition, which only allows the core to be displaced in the vertical direction and the horizontal direction is unconstrained. The mechanical parameters (e.g., Young's modulus, Poisson's ratio, compressive strength, yield strength, and shear modulus) are obtained by using ANSYS software. Thus, the RVE analysis of the rock skeleton on the microstructure parameters (e.g., tortuosity and TC) and mechanical parameters against the model size are conducted; the RVE analysis results of sample S5 are shown in Figure 5.
In order to reduce the size effect of the model, when the mechanical parameters are used for RVE analysis, the ratio of the output parameters to the input parameters is taken. As shown in Figure 5, all the parameters fluctuate greatly when the length of the model is between 100 and 250 pixels and approach steady when the length is beyond 300 pixels. Thus, the RVE of sample $S 5$ is 300 . Through the same methods, the optimal RVE of different rock samples is determined. Based on this, the finite element mesh model of each rock sample is established. The RVE parameters of the models S1, S2, S3, S4, and 55 are shown in Table 5. 
TABLE 5: Detailed parameters of RVEs of digital cores.

\begin{tabular}{|c|c|c|c|c|c|}
\hline Model & Mesh model volume $\left(\mathrm{m}^{3}\right)$ & Model mesh number & Porosity (\%) & Side length $(\mathrm{mm})$ & REV edge length (pixel) \\
\hline $\mathrm{S} 5_{300-1}$ & $2.29 \times 10^{-10}$ & 1408315 & 8.36 & 0.63 & \multirow{2}{*}{300} \\
\hline$S 5_{300-2}$ & $2.27 \times 10^{-10}$ & 1744435 & 9.07 & 0.63 & \\
\hline$S 5_{400-1}$ & $5.44 \times 10^{-10}$ & 3572342 & 8.30 & 0.84 & \multirow[b]{2}{*}{400} \\
\hline$S 5_{400-2}$ & $5.39 \times 10^{-10}$ & 3989611 & 8.39 & 0.84 & \\
\hline S1 & $1.81 \times 10^{-9}$ & 2787997 & 17.6 & 1.3 & \multirow{2}{*}{300} \\
\hline S2 & $7.97 \times 10^{-10}$ & 797051 & 20.3 & 1 & \\
\hline S3 & $2.6 \times 10^{-10}$ & 2072375 & 38.6 & 0.75 & \multirow{2}{*}{400} \\
\hline S4 & $5.96 \times 10^{-10}$ & 596233 & 40.4 & 1 & \\
\hline
\end{tabular}

\section{Pore Scale Simulation on Uniaxial Compression}

The optimal REV model is determined in Section 3.3. The uniaxial compression numerical simulation in this section is conducted on the RVE model. The averaged von Mises stress distribution, total displacement field, plastic strain field, and stress-strain curve are obtained. The following analysis is investigated by taking model S2 as an example.

Figure 6 shows averaged von Mises stress distribution of model S2 at the termination of displacement loading. The red and blue zones indicate the maximum and minimum stresses, respectively. It can be seen that stress concentration occurs on each loading surface, and the shape of the rock skeleton is extremely irregular in the stress concentration region. In the case of applying the same displacement, the stress of the rock sample in the $X$ direction is relatively uniform, and the stress distribution in the $Y$ direction is mainly concentrated in the right half of the rock sample. The compressive performance in the $X$ direction is significantly larger than that of the $Y$ direction. The existence of pores leads to nonuniform distribution of stress, which is shown in detail in Figure 7.

Figure 8 shows the distribution of the rock total displacement. The deformation of the model right part is serious, as shown in Figure $8(\mathrm{a})$, and it indicates that the compressive capacity of this part is relatively weak, and Figure $8(\mathrm{~b})$ is the opposite. During the deformation process of the rock, the displacement field exhibits the translational characteristics, and arch-shaped deformation regions are formed between the deformation zones. The slice displacement details of different spatial positions are shown in Figure 9.

Figure 10 is the plastic strain distribution of model S2, which directly reflects the deformation of the rock after yield. When the bearing capacity reaches the limit, plastic failure will occur in the rock. It can be seen from Figure 11 that at the end of displacement loading, plastic deformation passes through the pores, forming various shape shear zones. An obvious $X$-shaped plastic conjugate shear zone (red circle) is formed, as shown in Figure 10(a). Combining with the averaged von Mises stress distribution, the plastic failure priorly occurs where the stress is relatively high.

The stress-strain curves of different models are shown in Figure 12. In the process of numerical simulation, models S1-S2, S3-S4, and S5 $5_{300-1} \sim \mathrm{S} 5_{400-2}$ used three groups of input parameters. It can be seen that the stress-strain curve of the models varies with the loading directions, indicating the anisotropy and heterogeneity of the rock. The anisotropy of the models S1 to S4 is significantly higher than model S5 300 ${ }_{1} \sim S 5_{400-2}$. In model S1 S4, when the strain is about $0.5 \%$, the rock reaches the elastic limit and enters the plastic yield state. The yield strength of model S1 and S2 are about $40 \mathrm{MPa}$.

In model $\mathrm{S} 5_{300-1} \sim \mathrm{S} 5_{400-2}$, there is little difference in porosity, the compressive strength of rock is about $100 \mathrm{MPa}$, the yield strength is about $60 \mathrm{MPa}$, and mechanical parameters in each direction are not much different, indicating that the anisotropy of the rock is not obvious. When the strain is $1 \%$, the rock is destroyed and the compressive limit is reached. When the model reaches the compressive limit, the strain increases continuously, and the stress is almost constant. The reason is the plastic skeleton of the rock is assumed to be perfectly plastic when reaching the compressive strength.

\section{Analysis of Related Parameters of Digital Core}

5.1. Correlation Analysis between Porosity and Mechanical Parameters. Porosity refers to the ratio of pore volume to the entire volume of the rock sample, which is an important parameter used to characterize the rock microstructure. The mechanical parameters of different rock samples are obtained by numerical simulation and the relationship between porosity and mechanical parameters, as shown in Figure 13.

As shown in Figure 13(a), the ratio of Young's modulus of digital rock samples decreases linearly with the increase of porosity $\left(R^{2}=0.87\right)$. Moreover, it is found that the effective Young's modulus of the rock has a good exponential relationship with porosity $\left(R^{2}=0.975\right)$ by Cheng et al. [35]. In addition, Pabst et al. [47] also found Young's modulus has a good correlation with porosity from the perspective of the exponential model $\left(R^{2}=0.99\right)$. The fitting coefficient of the simulation is lower than that of the literature. The reason is that tight sandstone and loose sandstone from different sites are adopted in this study, while the rock samples are drilled from the same sites in the literature. In general, compressive strength decreases with the increase of the porosity. The ratio of compressive strength is negatively correlated with porosity (Figure 13 (b) $R^{2}=0.87$ ), the result is consistent with Zhou and Xiao [48]. The ratio of yield strength is shown in Figure $13(\mathrm{c})$ and its corresponding coefficient $R^{2}$ is 0.90 . The 


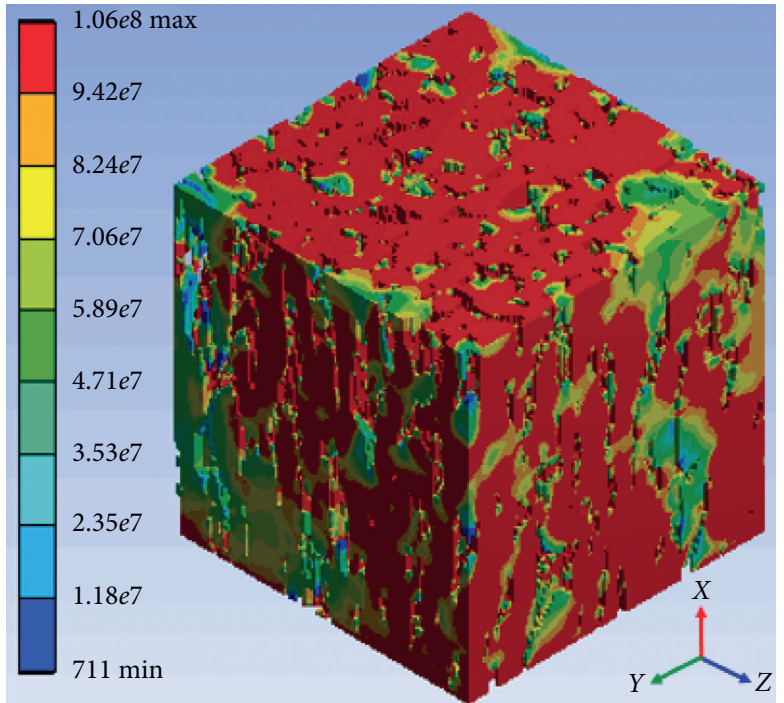

(a)

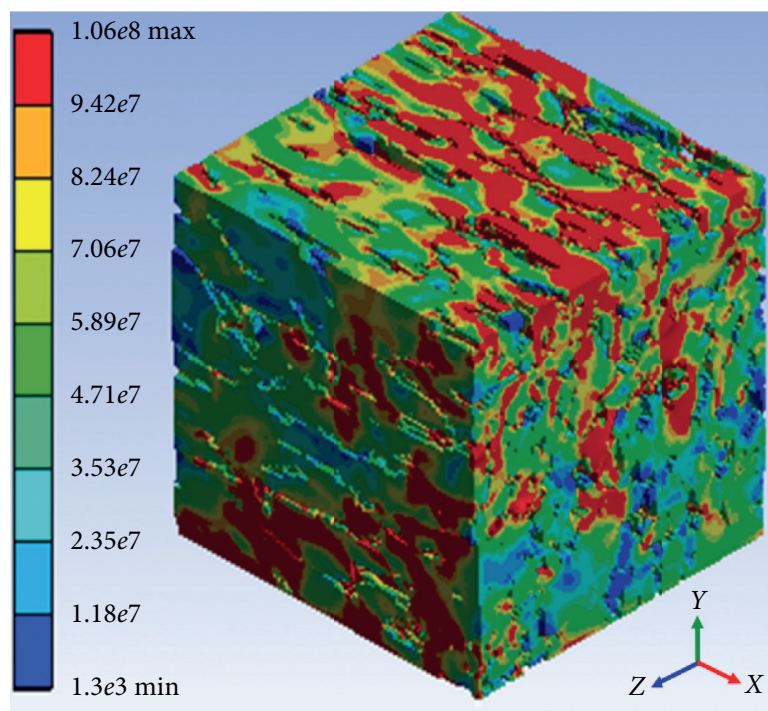

(b)

FIgURe 6: Averaged von Mises stress distribution of model S2 (unit: Pa) represents the loading applied (a) in $X$ direction and (b) in $Y$ direction.

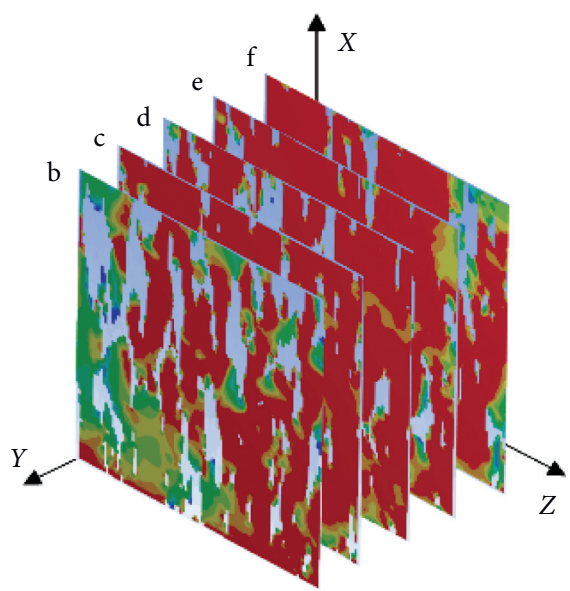

(a)

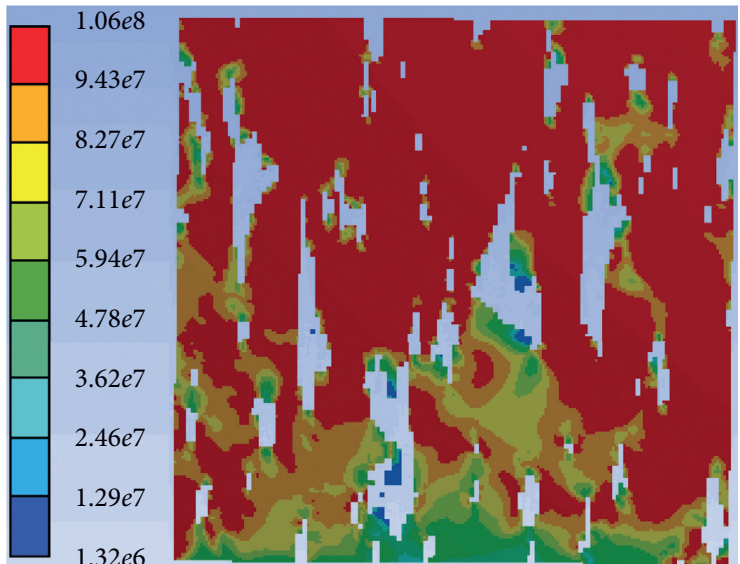

(c)

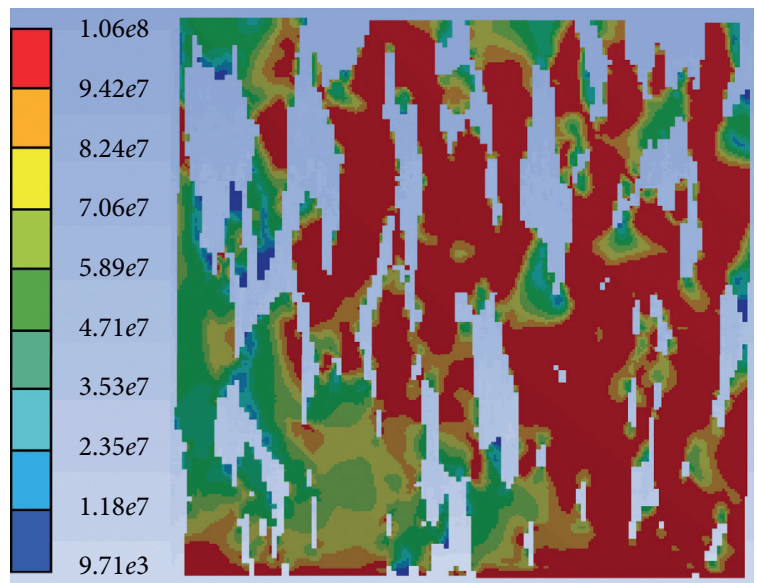

(b)

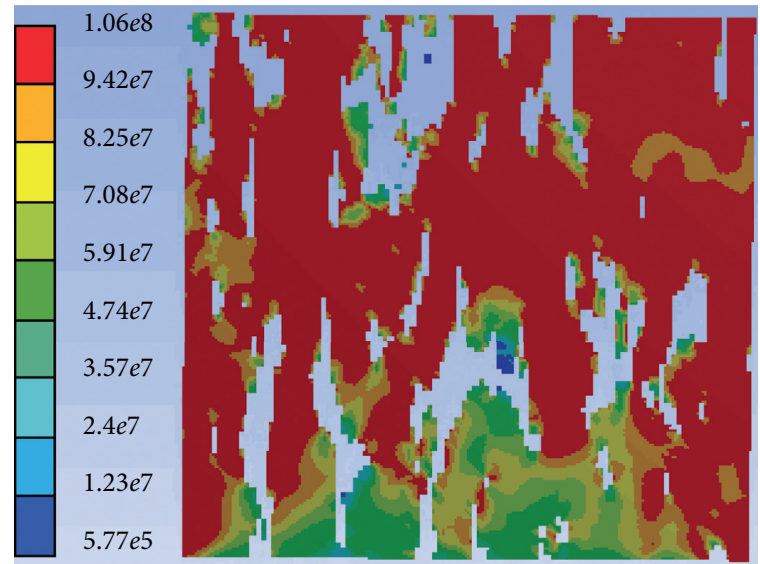

(d)

Figure 7: Continued. 


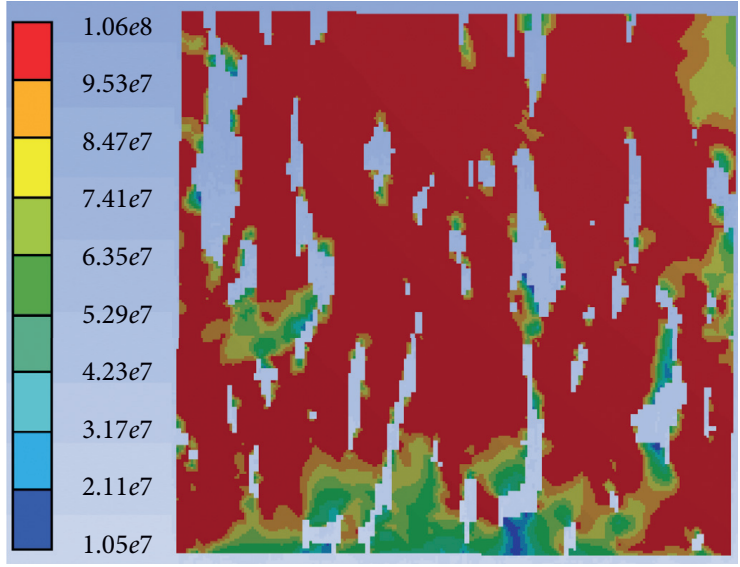

(e)

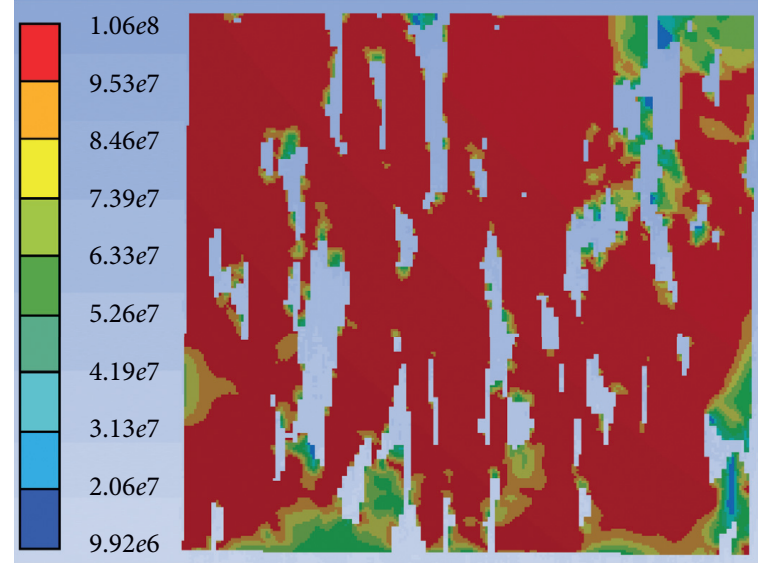

(f)

Figure 7: Cross-sections averaged von Mises stress distribution of model S2 (unit: Pa): (a) spatial location of slices at (b) $y=1 \mathrm{~mm}$, (c) $y=0.8 \mathrm{~mm}$, (d) $y=0.6 \mathrm{~mm}$, (e) $y=0.4 \mathrm{~mm}$, and (f) $y=0.2 \mathrm{~mm}$.

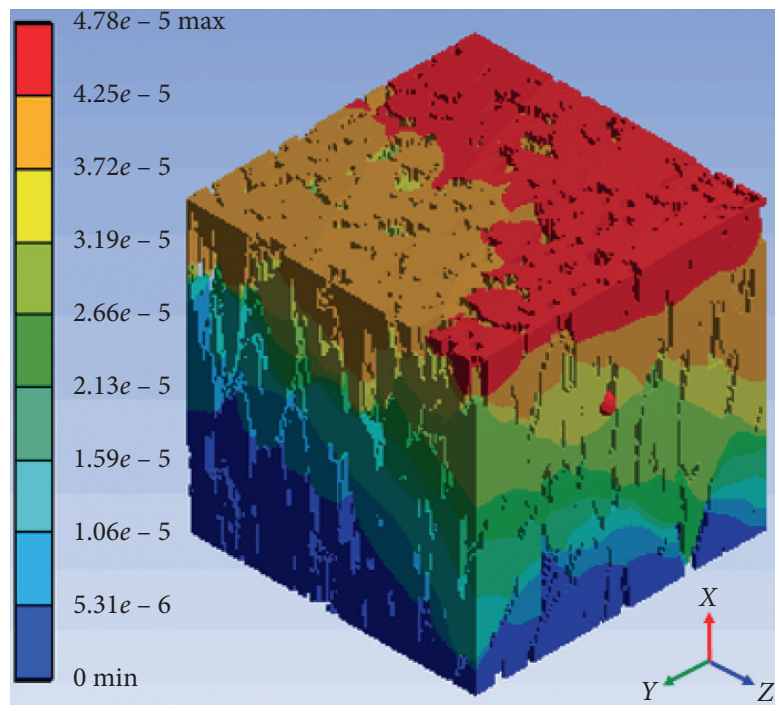

(a)

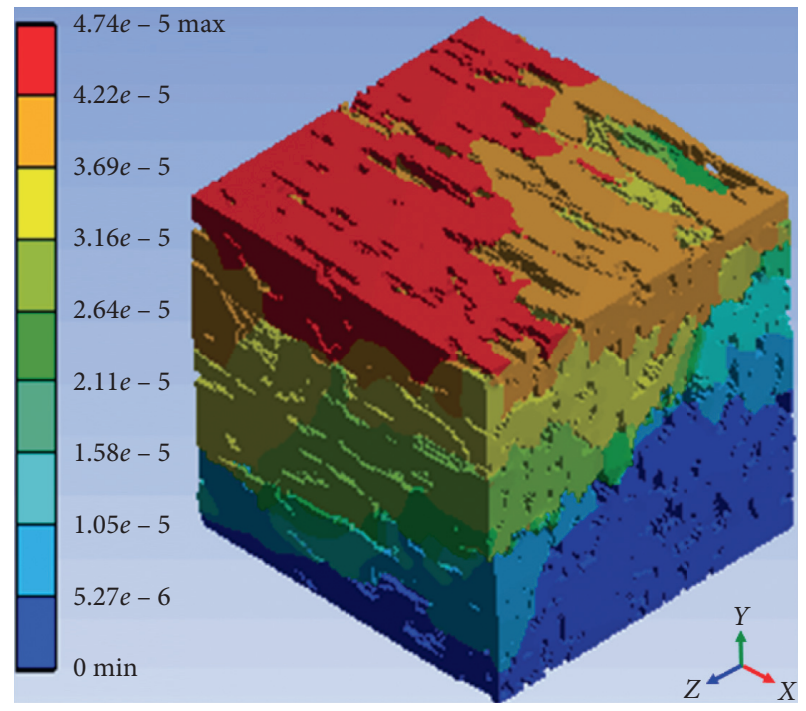

(b)

FIgURe 8: Total displacement distribution of model S2 (unit: $\mathrm{m}$ ) represents the loading applied (a) in $X$ direction and (b) in $Y$ direction.

ratio of shear modulus is deeply related to porosity, and the fitting curve is shown in Figure 13(d) $\left(R^{2}=0.84\right)$. With the increase of porosity, all mechanical parameters of the rock decrease linearly. The main reason is that the cementation becomes worse and the bearing capacity becomes weaker with the rising of porosity. However, for the same model with the same porosity, there are great differences in Young's modulus, compressive strength, yield strength, and shear modulus in different directions. It indicates that the porosity is possible to reproduce the anisotropy and heterogeneity of the rock microstructure.

5.2. Correlation Analysis between TC and Mechanical Parameters. TC is an important parameter to quantitatively describe the internal microstructure of the rock and evaluate the mechanical properties of the rock. As shown in Figure 14, with the increase of the TC value, the mechanical parameters of digital rock samples show logarithmic decline. In Figure 14(a), Young's modulus ratio of rock samples gradually decreases with the increase of TC, and its correlation coefficient $R^{2}$ is 0.83 . Meanwhile, the TC value has a high correlation with Young's modulus (Figure 14(b) $R^{2}=0.87$ ), yield strength (Figure $14(\mathrm{c}) R^{2}=0.89$ ), and shear modulus (Figure $14(\mathrm{~d}) R^{2}=0.85$ ). These fitting results are also consistent with the results of other scholars. Howarth and Rowlands [18] found the TC was highly correlated with the compressive strength $\left(R^{2}=0.92\right)$. The reported $R^{2}$ correlations of TC between compressive strength was 0.69 and Young's modulus was 0.69 by Erosy and Waller [19]. Alber and Kahraman [21] reported that the compressive strength of the prediction model had a very high correlation with TC 


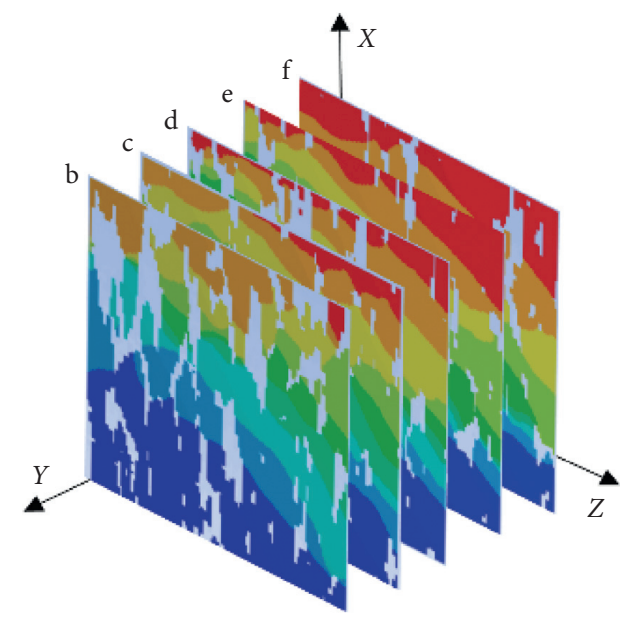

(a)

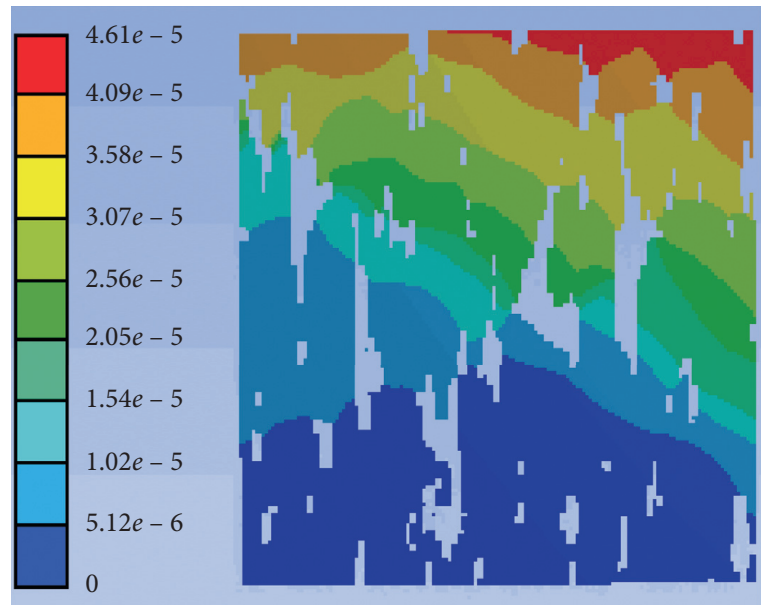

(c)

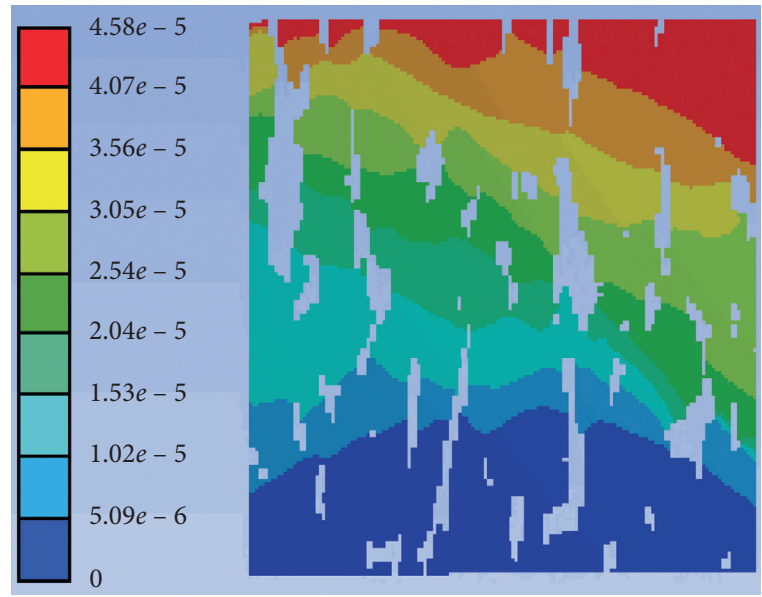

(e)

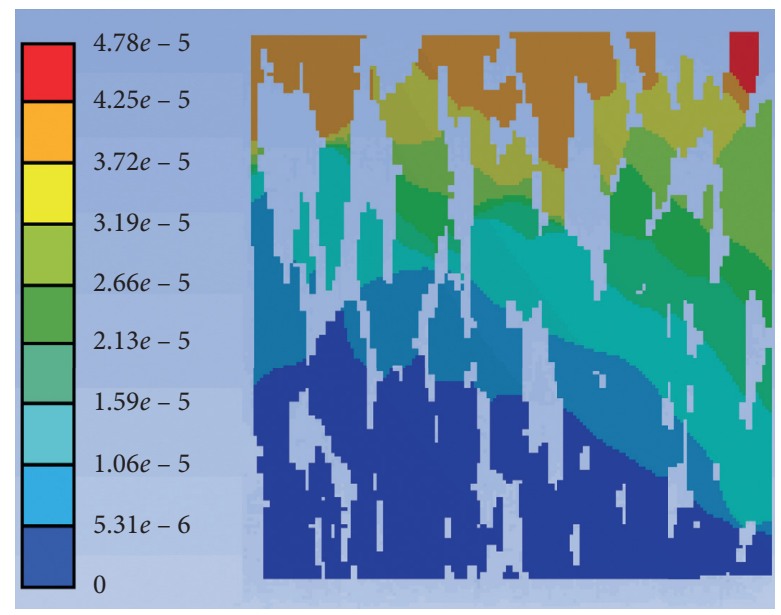

(b)

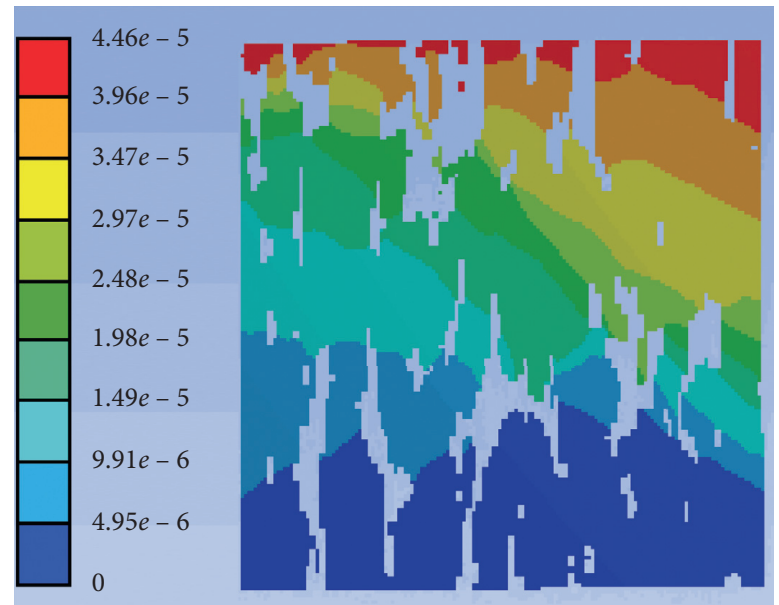

(d)

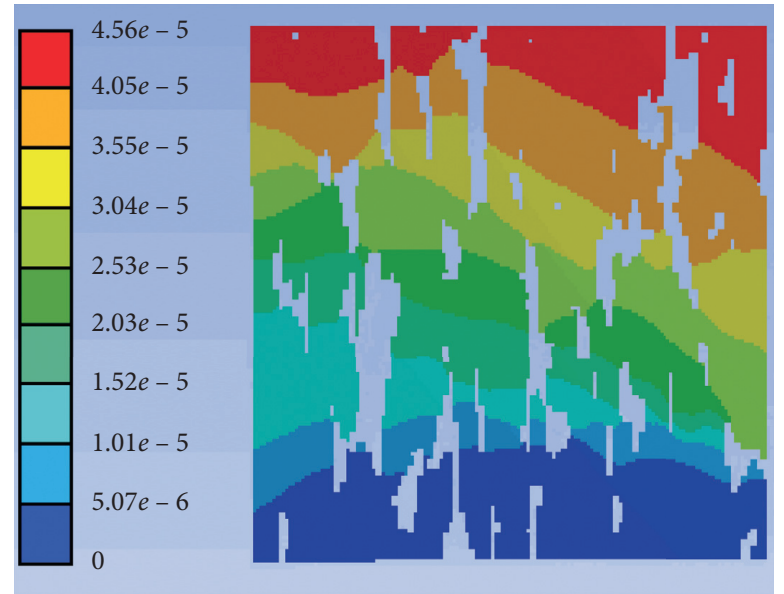

(f)

Figure 9: Cross-sections total displacement distribution of model S2 (unit: $\mathrm{m}$ ): (a) spatial location of slices at (b) $y=1 \mathrm{~mm}$, (c) $y=0.8 \mathrm{~mm}$, (d) $y=0.6 \mathrm{~mm}$, (e) $y=0.4 \mathrm{~mm}$, and (f) $y=0.2 \mathrm{~mm}$.

$\left(R^{2}=0.90\right)$. The difference between the results of this paper and the literature is that the pores are regarded as grains with a mechanical strength of 0 , while the TC of the grains was investigated in the literature. According to the definition of
TC, it is determined by the number, shape, and randomness of the orientation of the pores. Prikryl [49] found mechanical properties of rocks which have been mostly affected by variable number, shape, and orientation of grains in some 


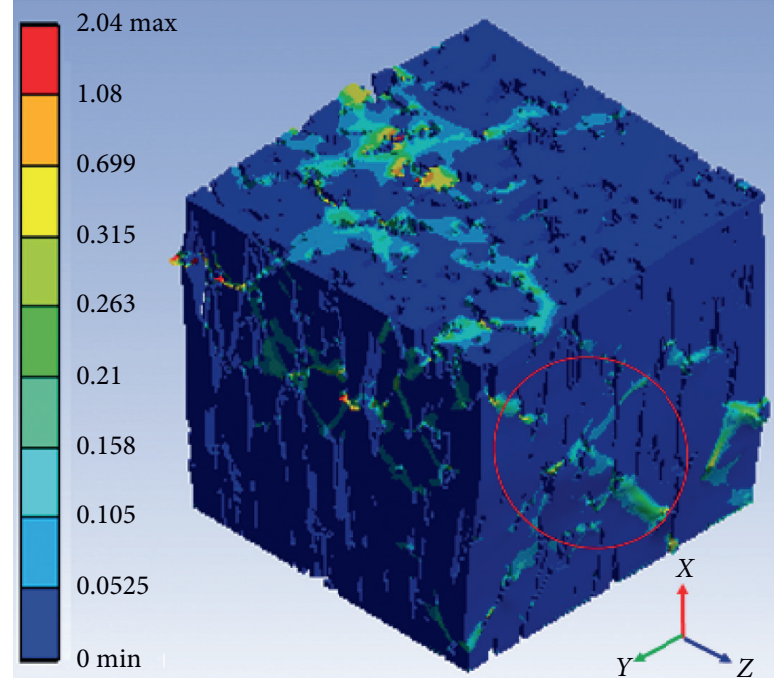

(a)

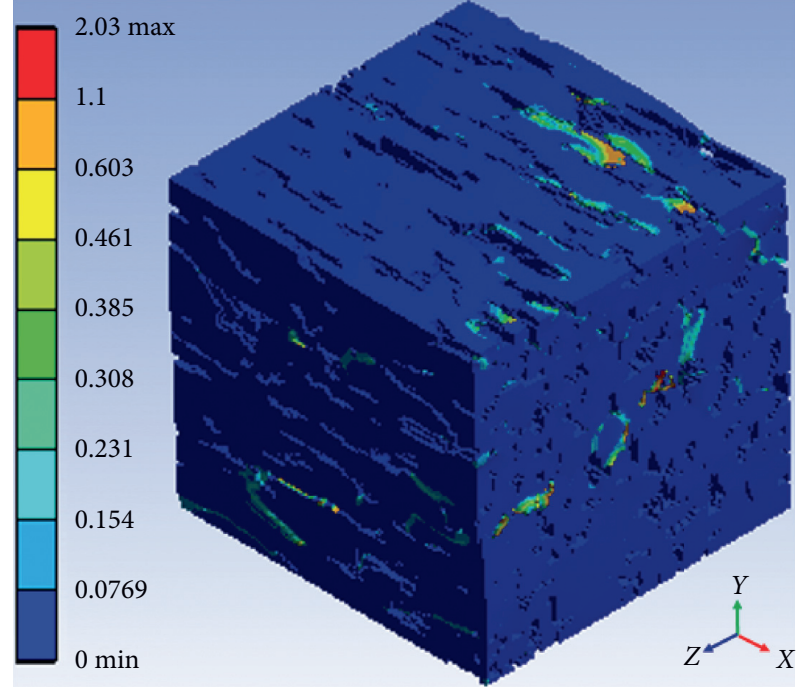

(b)

FIgURE 10: Plastic stain distribution of model S2 represents the loading applied (a) in $X$ direction and (b) in $Y$ direction.

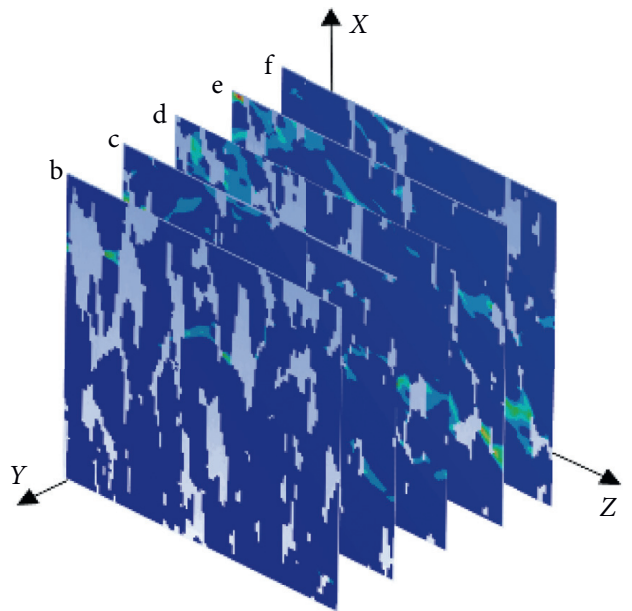

(a)

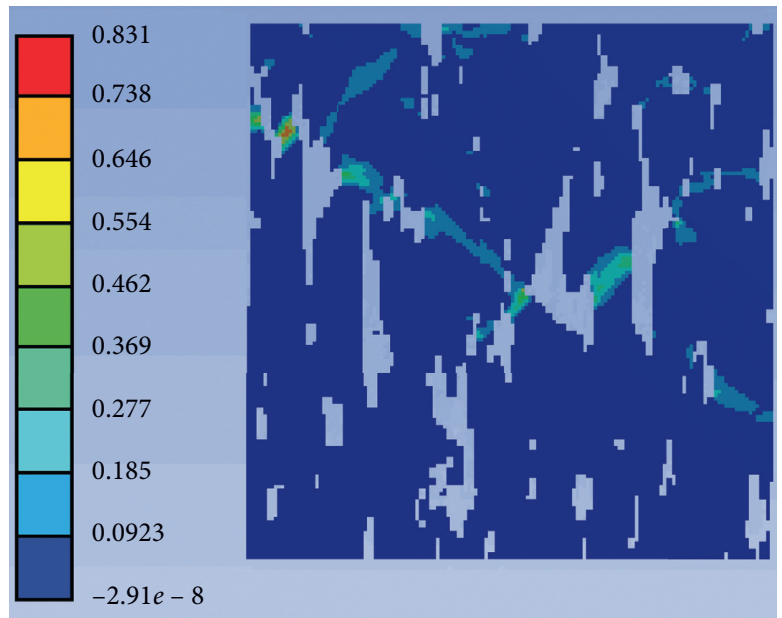

(c)

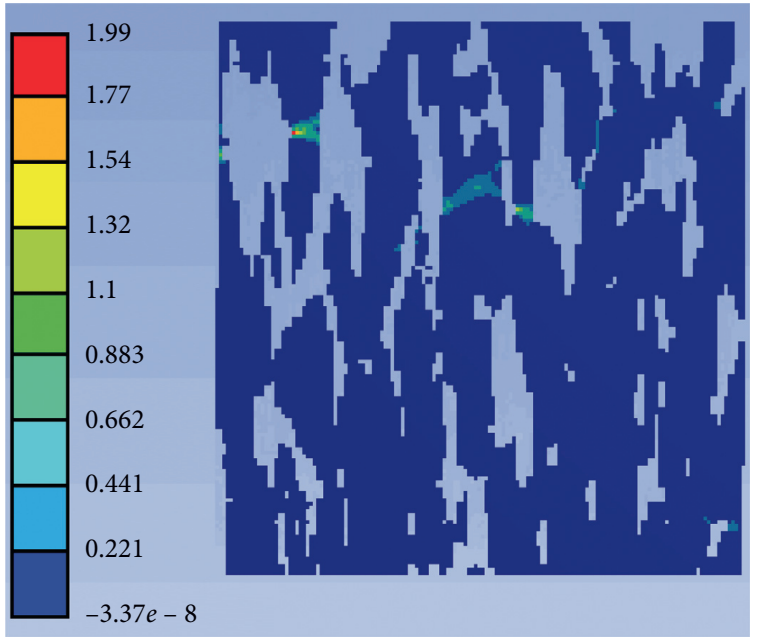

(b)

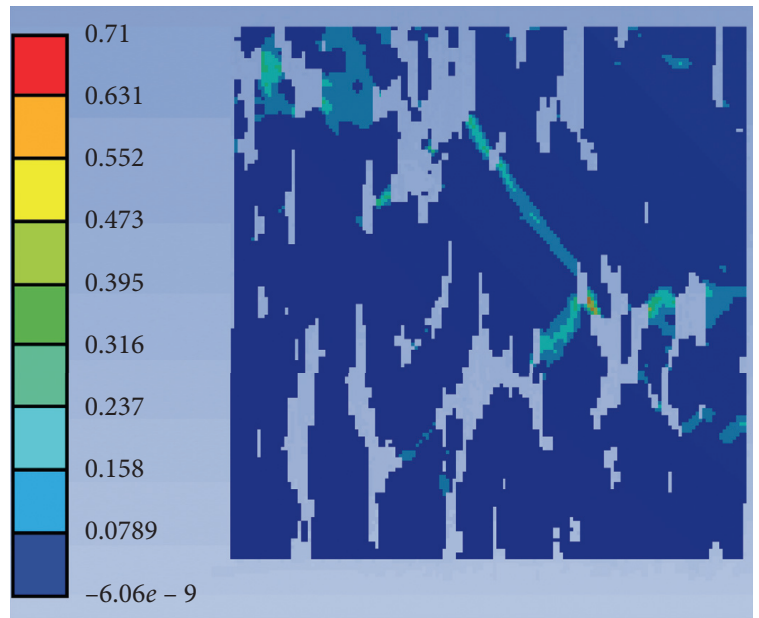

(d)

Figure 11: Continued. 


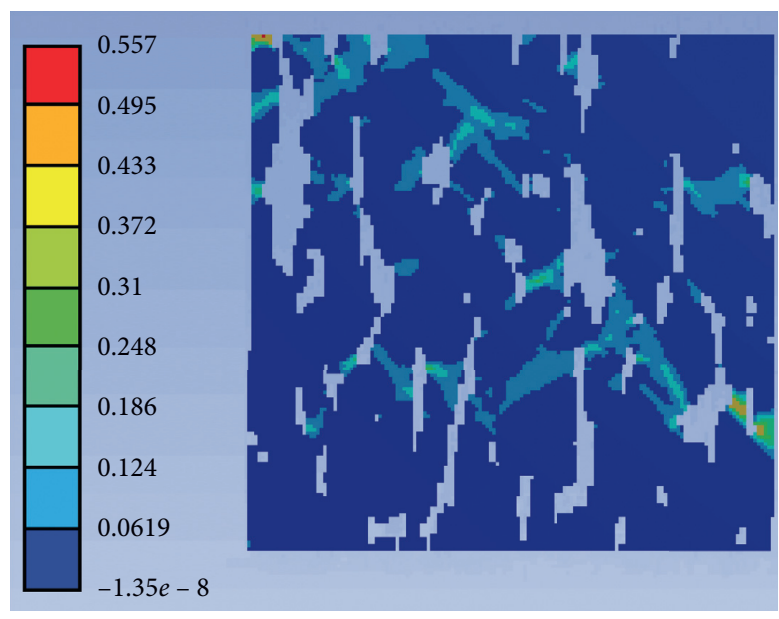

(e)

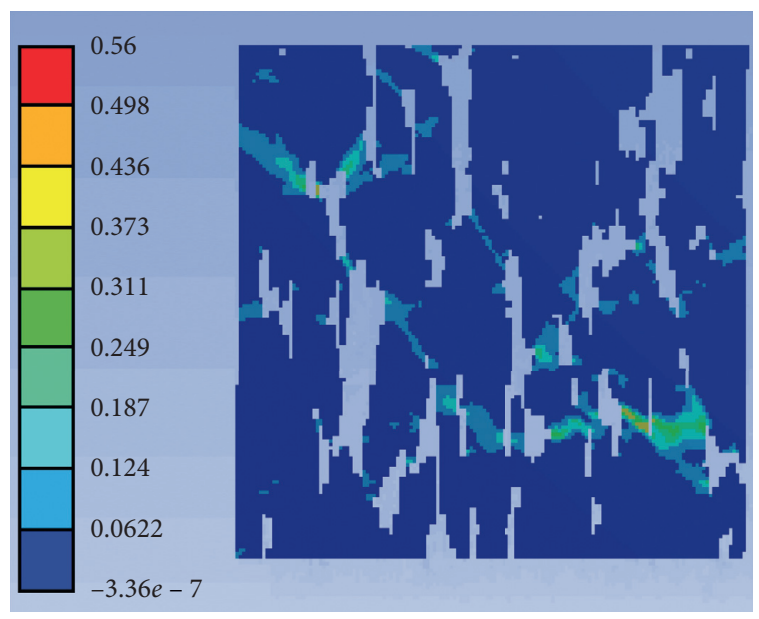

(f)

Figure 11: Cross-sections plastic strain distribution of model S2: (a) spatial location of slices at (b) $y=1 \mathrm{~mm},(\mathrm{c}) y=0.8 \mathrm{~mm}$, (d) $y=0.6 \mathrm{~mm}$, (e) $y=0.4 \mathrm{~mm}$, and (f) $y=0.2 \mathrm{~mm}$.

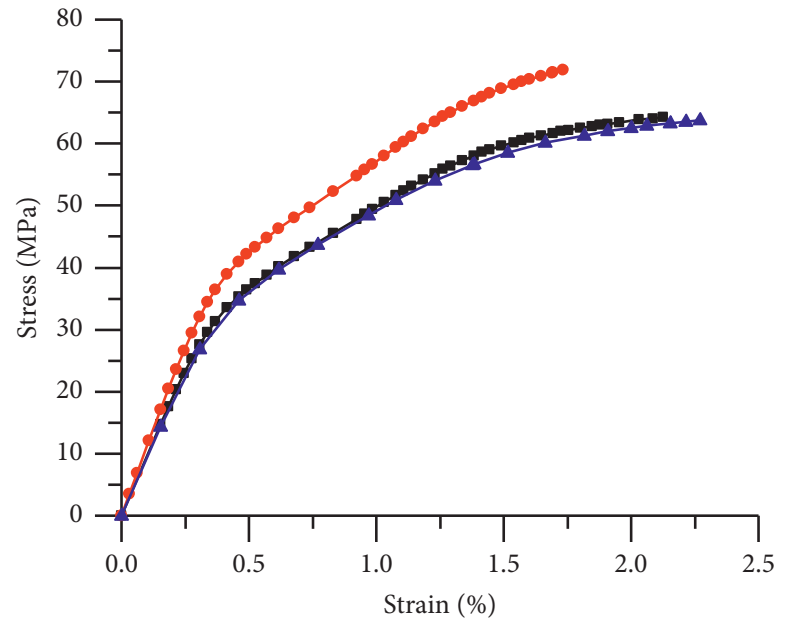

$\rightarrow X$
$\rightarrow Y$
$\leftarrow Z$

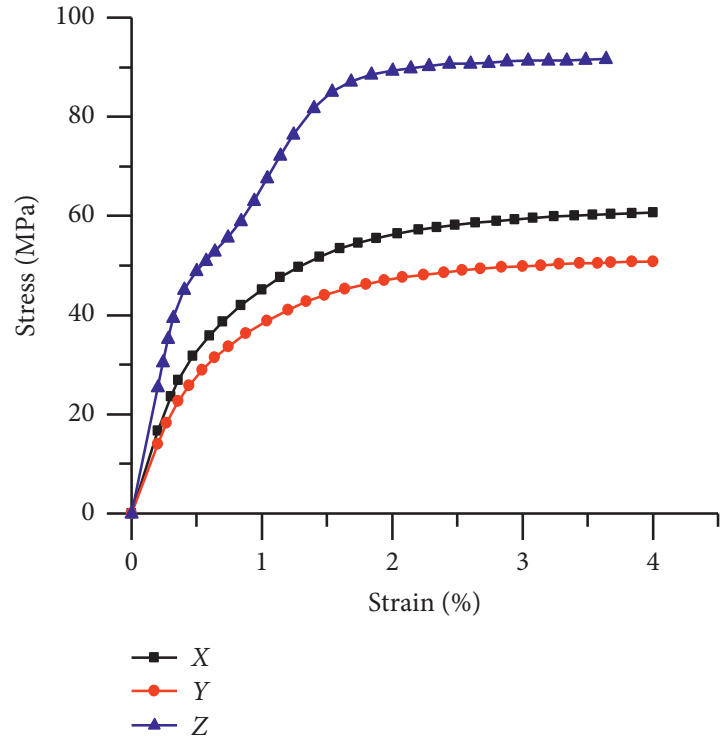

(b)

Figure 12: Continued. 

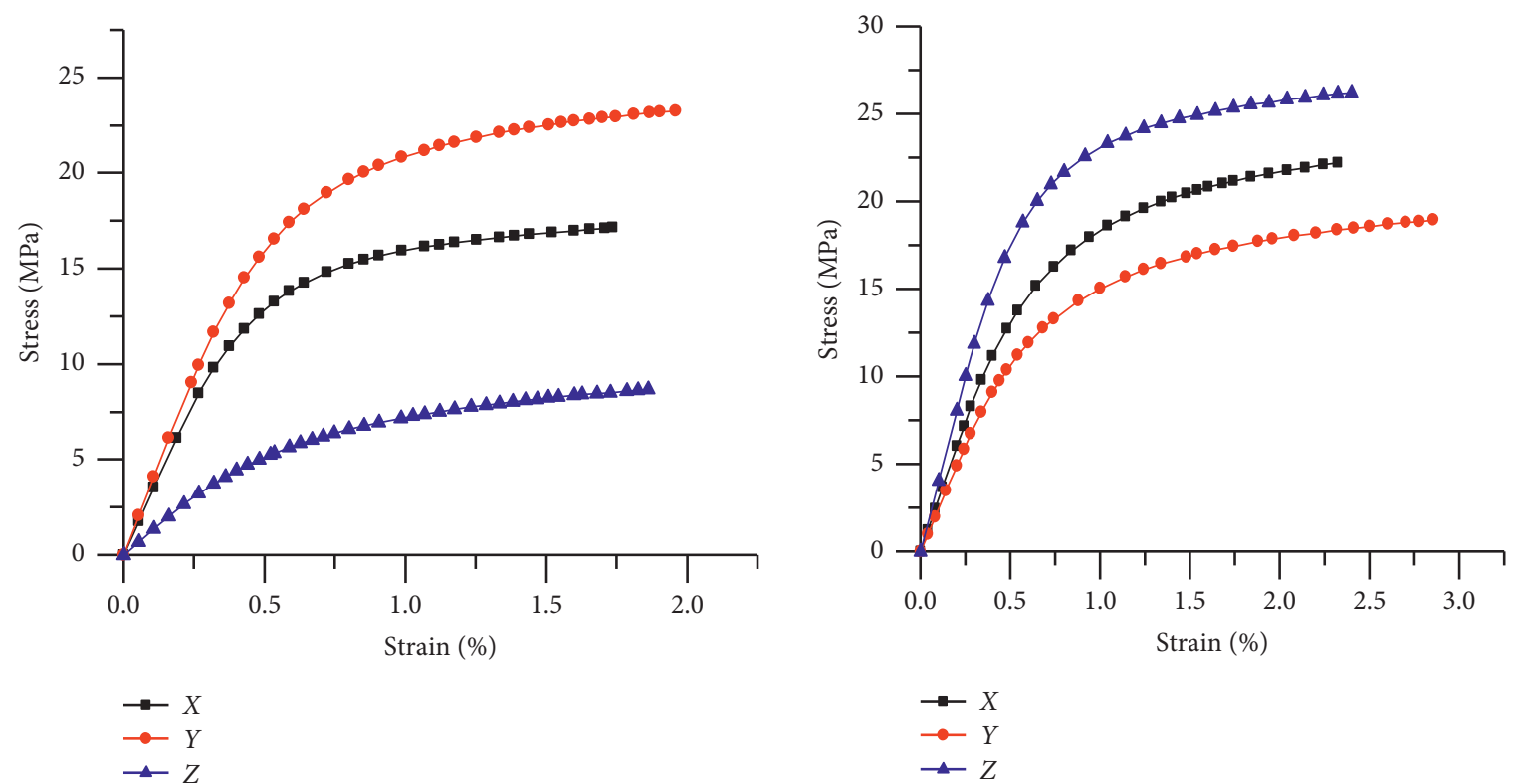

(c)
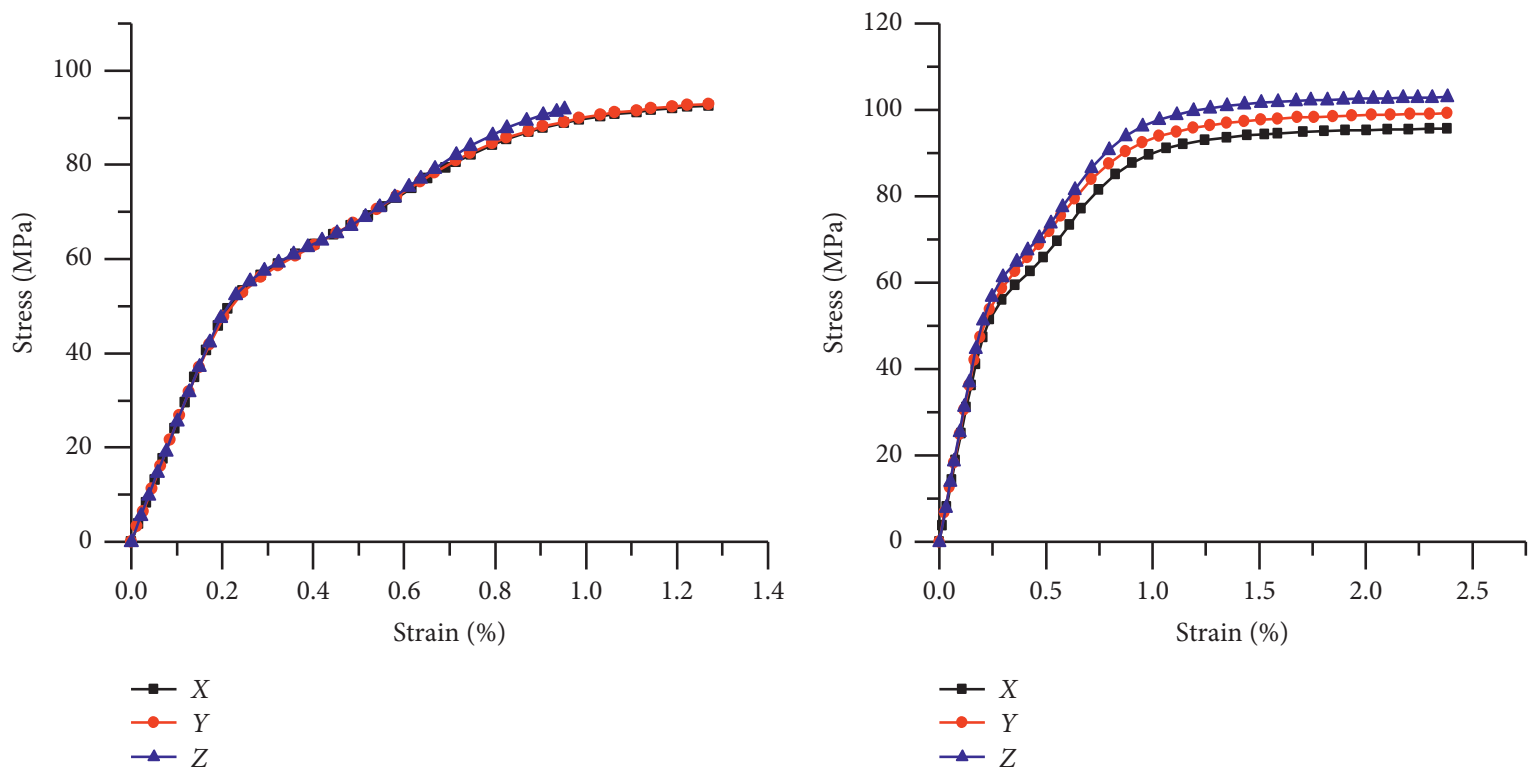

(e)

Figure 12: Continued. 


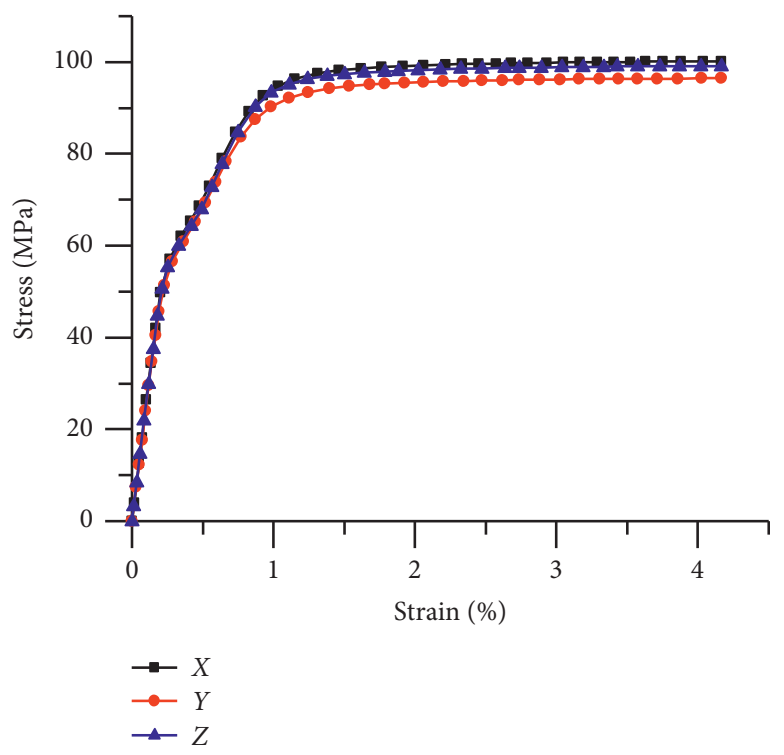

$(\mathrm{g})$

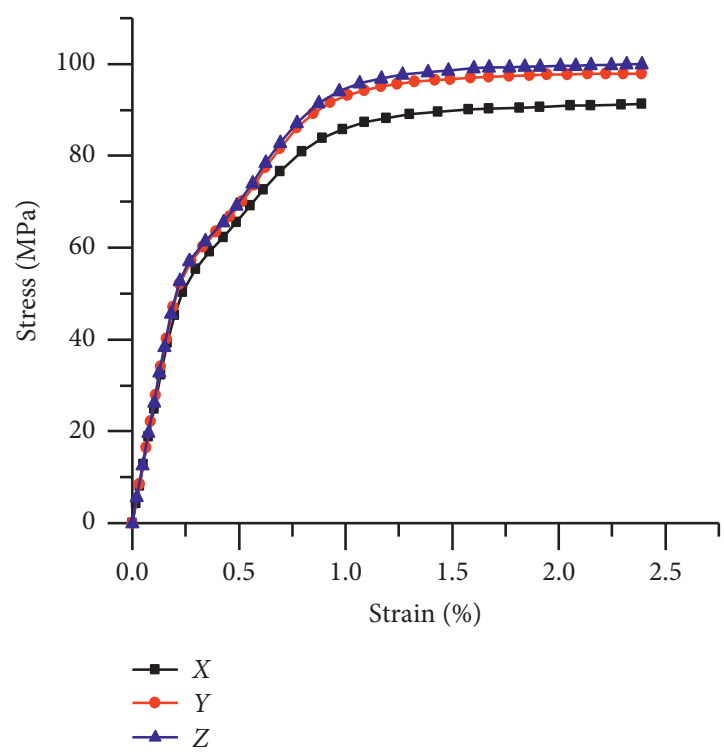

(h)

FIGURE 12: Stress-strain curves of digital rock samples. (a) (h) are the stress-strain curves of model S1, S2, S3, S4, S5 $5_{300-1}, \mathrm{~S}_{300-2}, \mathrm{~S}_{400-1}$, and $\mathrm{S}_{400-2}$. (a) $\varphi=17.6 \%$. (b) $\varphi=20.3 \%$. (c) $\varphi=38.6 \%$. (d) $\varphi=40.4 \%$. (e) $\varphi=8.36 \%$. (f) $\varphi=9.07 \%$. (g) $\varphi=8.3 \%$. (h) $\varphi=8.39 \%$.

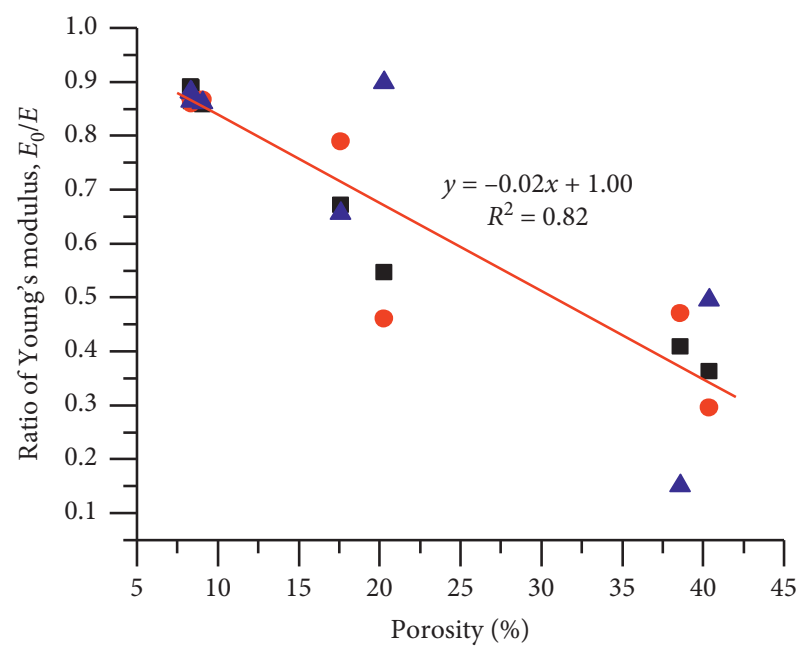

- $X$

$Y$

$\Delta Z$

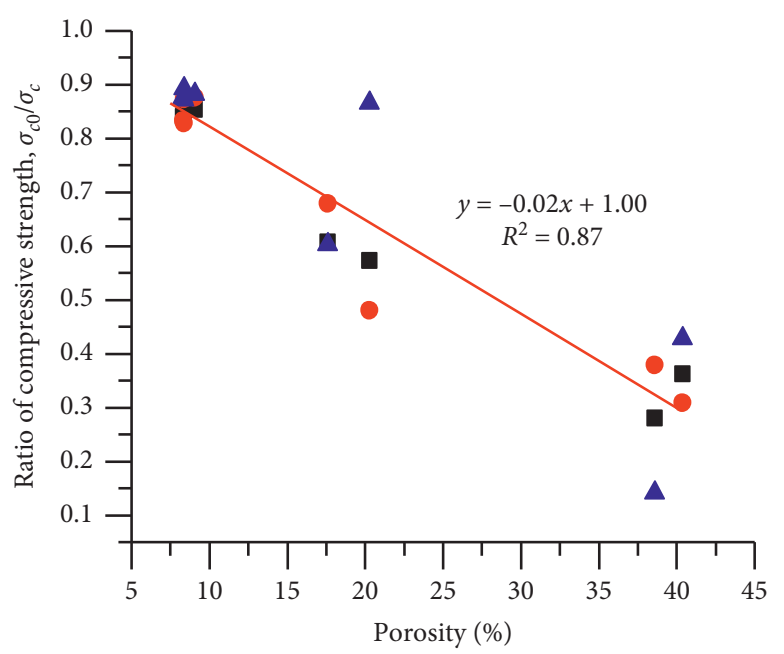

口 $X$

- $Y$

- $Z$

(a)

(b)

FIgURE 13: Continued. 

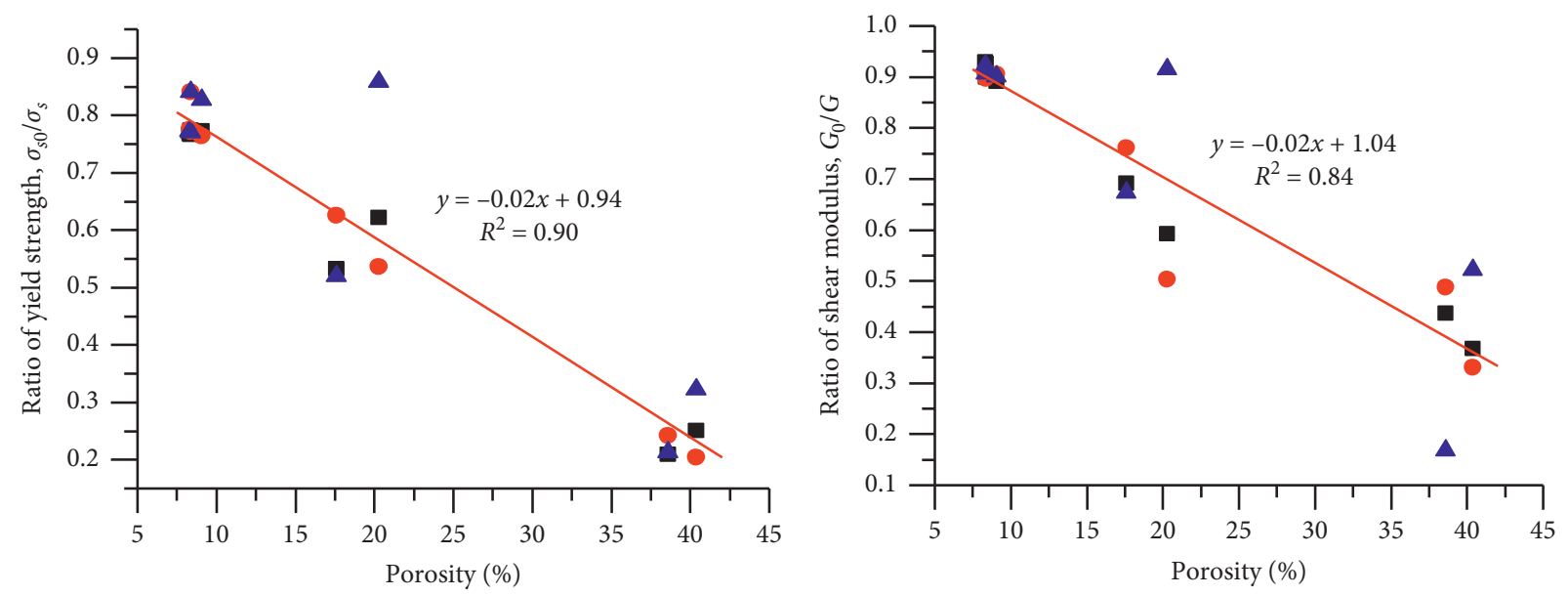

$X$
- $Y$
- $Z$

- $X$

Y

(c)

(d)

FIGURE 13: Correlation analysis between porosity and rock mechanics parameters. (a) (d) are the ratio of Young's modulus, ratio of compressive strength, ratio of yield strength, and ratio of shear modulus against the model porosity for correlation analysis.

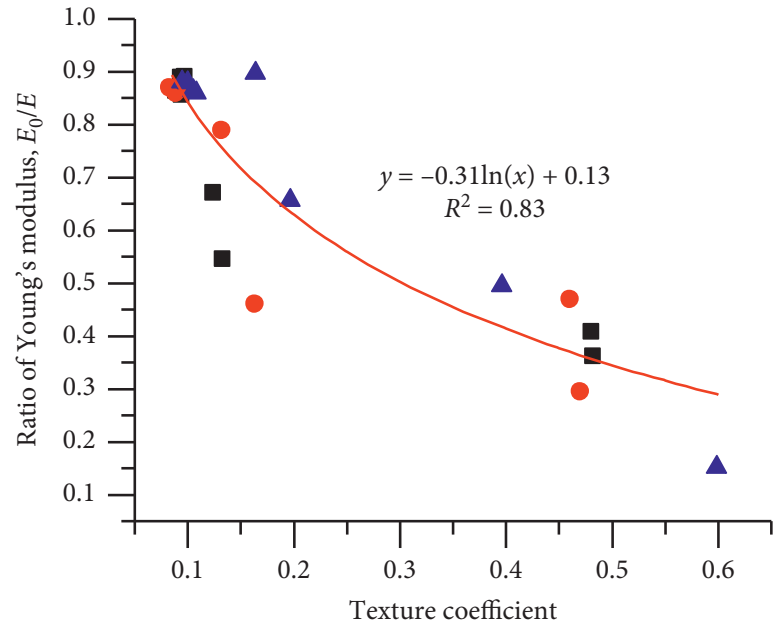

- $X$

- $Y$

- $Z$

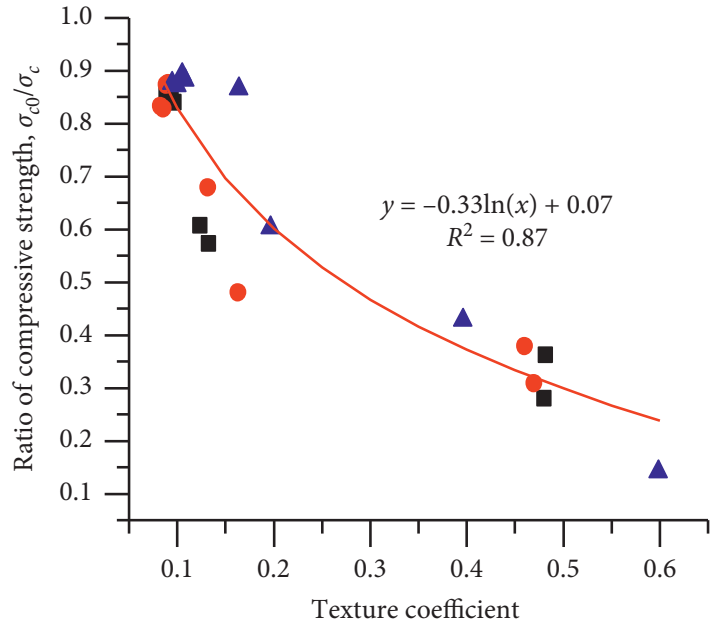

- $X$

- $Y$

- $Z$

(a)

(b)

Figure 14: Continued. 


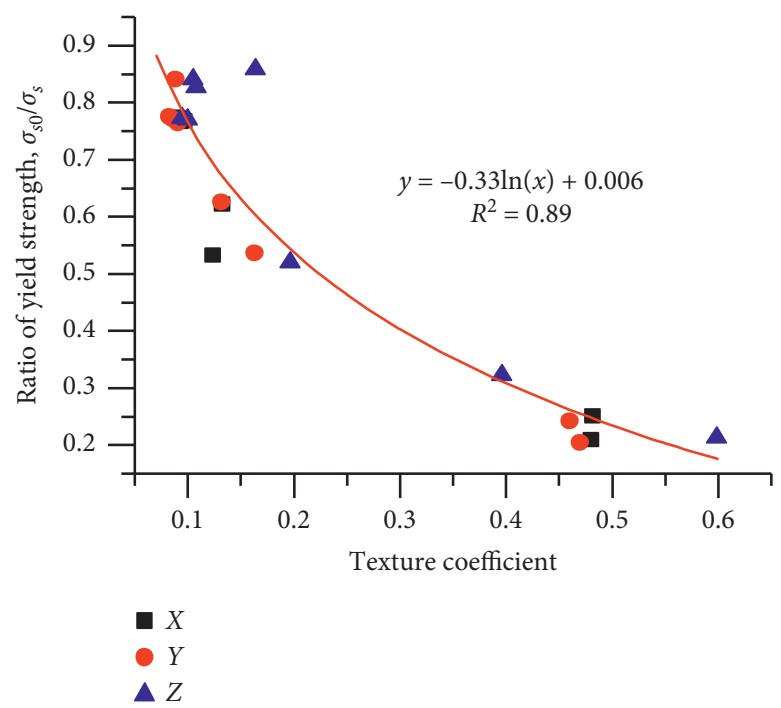

(c)

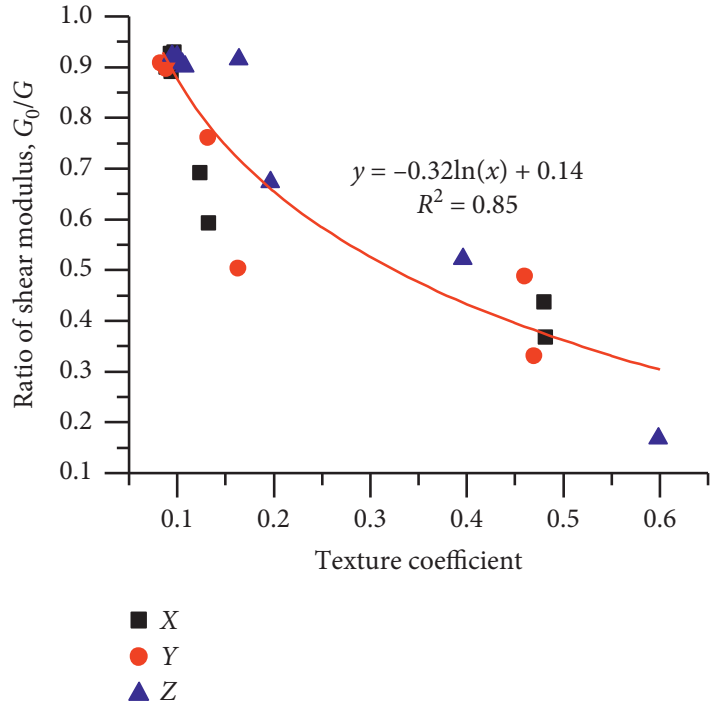

(d)

Figure 14: Correlation analysis between TC and digital core mechanical parameters. (a) (d) are the ratio of Young's modulus, ratio of compressive strength, ratio of yield strength, and ratio of shear modulus against the model TC for correlation analysis.
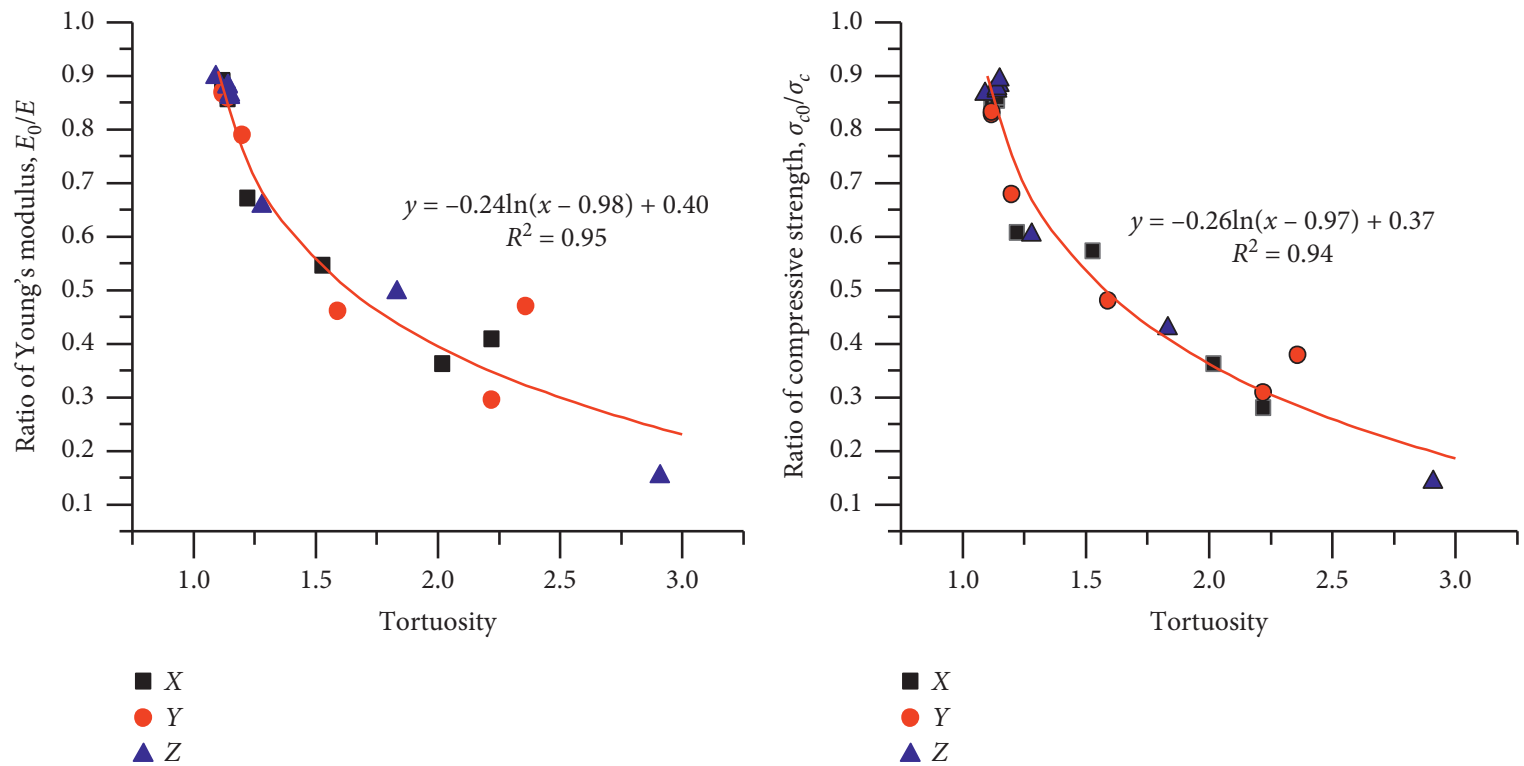

(a)

(b)

Figure 15: Continued. 


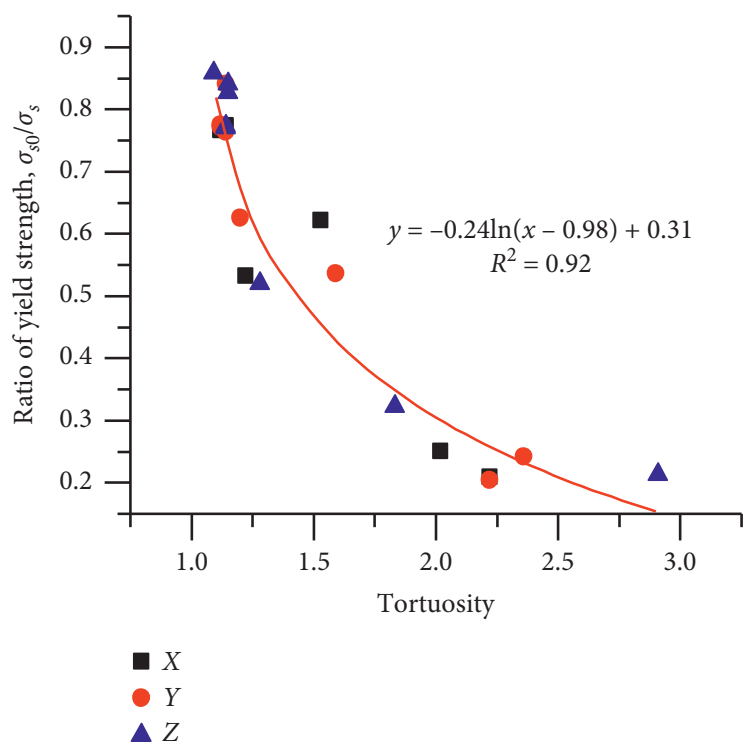

(c)

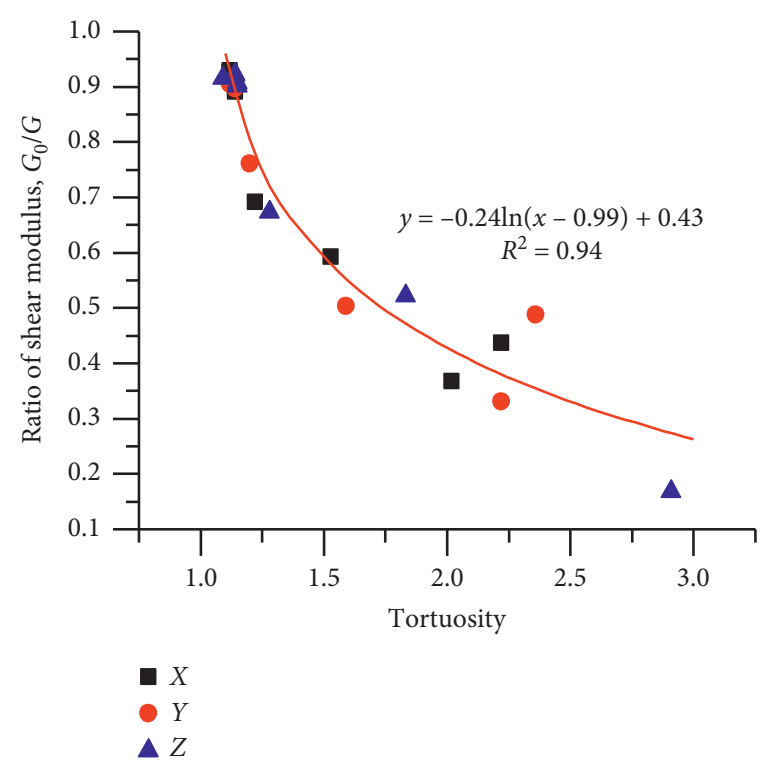

(d)

FiguRe 15: Correlation analysis between the tortuosity and the mechanical parameters of the digital core. (a) (d) are the ratio of Young's modulus, ratio of compressive strength, ratio of yield strength, and ratio of shear modulus against the model tortuosity for correlation analysis.

TABLE 6: Correlation between porosity, TC, tortuosity and mechanical parameters.

\begin{tabular}{lccc}
\hline Microstructural parameters & Mechanical parameters & Fitting formula & Correlation coefficient $R^{2}$ \\
\hline & Ratio of Young's modulus $\left(E_{0} / E\right)$ & $E_{0} / E=-0.02 \varphi+1.00$ & 0.82 \\
Porosity $(\varphi)$ & Ratio of compressive strength $\left(\sigma_{C 0} / \sigma_{C}\right)$ & $\sigma_{C 0} / \sigma_{C}=-0.02 \varphi+1.00$ & 0.87 \\
& Ratio of yield strength $\left(\sigma_{S 0} / \sigma_{S}\right)$ & $\sigma_{S 0} / \sigma_{S}=-0.02 \varphi+0.94$ & 0.90 \\
& Ratio of shear modulus $\left(G_{0} / G\right)$ & $G_{0} / G=-0.02 \varphi+1.04$ & 0.84 \\
\hline & Ratio of Young's modulus $\left(E_{0} / E\right)$ & $E_{0} / E=-0.31 \ln (\mathrm{TC})+0.13$ & 0.83 \\
Texture coefficient $(\mathrm{TC})$ & Ratio of compressive strength $\left(\sigma_{C 0} / \sigma_{C}\right)$ & $\sigma_{C 0} / \sigma_{C}=-0.33 \ln (\mathrm{TC})+0.07$ & 0.87 \\
& Ratio of yield strength $\left(\sigma_{S 0} / \sigma_{S}\right)$ & $\sigma_{S 0} / \sigma_{S}=-0.33 \ln (\mathrm{TC})+0.006$ & 0.89 \\
& Ratio of shear modulus $\left(G_{0} / G\right)$ & $G_{0} / G=-0.32 \ln (\mathrm{TC})+0.14$ & 0.85 \\
\hline \multirow{5}{*}{ Tortuosity $(\tau)$} & Ratio of Young's modulus $\left(E_{0} / E\right)$ & $E_{0} / E=-0.24 \ln (\tau-0.98)+0.40$ & 0.95 \\
& Ratio of compressive strength $\left(\sigma_{C 0} / \sigma_{C}\right)$ & $\sigma_{C 0} / \sigma_{C}=-0.26 \ln (\tau-0.97)+0.37$ & 0.94 \\
& Ratio of yield strength $\left(\sigma_{S 0} / \sigma_{S}\right)$ & $\sigma_{S 0} / \sigma_{S}=-0.24 \ln (\tau-0.98)+0.31$ & 0.92 \\
& Ratio of shear modulus $\left(G_{0} / G\right)$ & $G_{0} / G=-0.24 \ln (\tau-0.99)+0.43$ & 0.94 \\
\hline
\end{tabular}

samples. TC increases with the rising of the proportion and aspect ratio of pores [18]. Compared to the porosity, TC varies with directions for the same model, which is able to represent the anisotropy and heterogeneity of the rock microstructure.

\subsection{Correlation Analysis between Tortuosity and Mechanical} Parameters. The tortuosity has been regarded as an important parameter of the microstructure for porous media, which is related to the porosity and grain radius as well as permeability. Salem and Chilingarian [50] found the variation of tortuosity depends on the internal structure and the composition, such as the orientation of grains, pore-water salinity, degree of compaction, and flow direction. Wang et al. [51] proposed the inverse correlations between tortuosity and permeability. Attia [52] found the tortuosity factor varies with many parameters, e.g., the geometry of porous media, the number of fine grains, and cementation factor. These researchers mainly studied the tortuosity of fluid flowing through pore channels and analyzed the influencing factors of tortuosity. However, the quantitative characterization of rock mechanical properties by tortuosity has not been found in existing studies. In this paper, it is proposed for the first time to analyze the mechanical properties of the rock by using tortuosity of the rock skeleton. The correlations between the tortuosity of the digital rock sample skeleton and the mechanical parameters of the digital cores are shown in Figure 15. It is observed from Figure 15(a) that with the increase of the tortuosity of the rock skeleton, the ratio of Young's modulus of digital rock samples shows logarithmic decrement $\left(R^{2}=0.95\right)$. Moreover, the ratio of compressive strength, yield strength, and shear modulus are in good correlation with the tortuosity of the rock skeleton, and the fitting coefficients are $0.94,0.92$, and 0.94 , respectively. The corresponding fitting 
curves are depicted in Figures 15(b)-15(d). It is assumed that the rock is composed of the skeleton and pore. When calculating the tortuosity of the rock skeleton, the skeleton of the rock is taken as the pore channel of fluid. The greater the tortuosity of the rock skeleton is, the longer the distance for the fluid pass through is. It indicates that the more pores there are, the worse the mechanical properties of the rock will be.

The porosity and TC are well-known parameters describing the features of the rock interior. The tortuosity of the rock skeleton is firstly used to characterize the microstructure of the rock. The correlations between the three parameters and the mechanical properties of rock are presented in Table 6. It can be seen from the table that the porosity, TC, and tortuosity all affect the mechanical parameters of the rock, while the correlation between the tortuosity and the rock mechanical parameters is higher than that of the porosity and TC. Thus, the tortuosity of the rock skeleton is believed to be more feasible to reveal the impacts of the microstructure of the rock on its mechanical properties.

\section{Conclusions}

Different types of sandstones are imaged using micro-CT technology. The rock porosity, the texture coefficient (TC), and the tortuosity of the rock skeleton are used to characterize the microscopic structure of the rock. Meanwhile, pore scale finite element mesh models of the rock with different pore structures are established. Combining with the rock mechanical parameters obtained in the laboratory, the microscale numerical simulation of uniaxial compression of the rock is carried out by ANSYS software. The following conclusions can be made:

(1) Through the uniaxial compression simulation of 12 digital cores in the $X, Y$, and $Z$ directions, the optimal $\mathrm{REV}$ of different rock samples is determined.

(2) In model S1 S4, when the strain is about $0.5 \%$, the rock reaches the elastic limit and enters the plastic yield state. In model $S 5_{300-1} \sim S 5_{400-2}$, there is little difference in porosity, the compressive strength of rock is about $100 \mathrm{MPa}$, and the yield strength is about $60 \mathrm{MPa}$. When the strain is about $1 \%$, plastic failure occurs in rocks.

(3) The relationships between the mechanical parameters of rock and the porosity, texture coefficient (TC), and the tortuosity of rock skeleton are fitted quantitatively. With the increase of porosity, mechanical parameters of digital rock samples decrease linearly. Moreover, with the increase of TC, mechanical parameters of the rock are logarithmically decreasing. In addition, the tortuosity of the rock skeleton is also highly correlated with the mechanical parameters of the rock, i.e., Young's modulus $\left(R^{2}=0.95\right)$, compressive strength $\left(R^{2}=0.94\right)$, yield strength $\left(R^{2}=0.92\right)$, and shear modulus $\left(R^{2}=0.94\right)$. The tortuosity of the rock skeleton is prior to the other two parameters in reproducing the anisotropy of the rock microstructure with the highest fitted correlation coefficient. Thus, the tortuosity of the rock skeleton, firstly presented in this paper, is believed to be more feasible to reveal the impacts of the microstructure of the rock on its mechanical properties.

\section{Data Availability}

The data used to support the findings of this study are available from the corresponding author upon request.

\section{Conflicts of Interest}

The authors declare that there are no conflicts of interest regarding the publication of this paper.

\section{Acknowledgments}

The authors greatly appreciate the financial support of the National Natural Science Foundation of China (Grant no. 51909225), National Science and Technology Major Project of China (Grant no. 2017ZX05013001-002), Open Research Fund of State Key Laboratory of Geomechanics and Geotechnical Engineering, Institute of Rock and Soil Mechanics, Chinese Academy of Sciences (Grant no. Z017009), and China Scholarship Council.

\section{References}

[1] S. C. Blair and N. G. W. Cook, "Analysis of compressive fracture in rock using statistical techniques: part I. A nonlinear rule-based model," International Journal of Rock Mechanics and Mining Sciences, vol. 35, no. 7, pp. 837-848, 1998.

[2] R. Song, M. Cui, and J. Liu, "Single and multiple objective optimization of a natural gas liquefaction process," Energy, vol. 124, pp. 19-28, 2017.

[3] X. H. Ni, X. M. Shen, and Z. H. Zhu, "Microscopic characteristics of fractured sandstone after cyclic freezing-thawing and triaxial unloading tests," Advances in Civil Engineering, vol. 2019, Article ID 6512461, 11 pages, 2019.

[4] R. A. Johns, J. S. Steude, L. M. Castanier, and P. V. Roberts, "Nondestructive measurements of fracture aperture in crystalline rock cores using X ray computed tomography," Journal of Geophysical Research: Solid Earth, vol. 98, no. B2, pp. 1889-1900, 1993.

[5] H. Kawakata, A. Cho, T. Yanagidani, and M. Shimada, "The observations of faulting in Westerly granite under triaxial compression by X-ray CT scan," International Journal of Rock Mechanics Mining Sciences, vol. 34, no. 3-4, pp. 151.e1151.e12, 1997.

[6] R. Song, Y. Wang, J. Liu, M. Cui, and Y. Lei, "Comparative analysis on pore-scale permeability prediction on micro-CT images of rock using numerical and empirical approaches," Energy Science \& Engineering, vol. 7, no. 6, pp. 2842-2854, 2019.

[7] V. G. R. D. Argandoña, A. R. Rey, C. Celorio, and L.M.S. D. Río, L. Calleja, J. Llavona, Characterization by computed X-ray tomography of the evolution of the pore structure of a dolomite rock during freeze-thaw cyclic tests," Physics and Chemistry of the Earth, Part A: Solid Earth and Geodesy, vol. 24, no. 7, pp. 633-637, 1999.

[8] H. Kawakata, A. Cho, T. Kiyama, T. Yanagidani, K. Kusunose, and M. Shimada, "Three-dimensional observations of faulting 
process in Westerly granite under uniaxial and triaxial conditions by X-ray CT scan," Tectonophysics, vol. 313, no. 3, pp. 293-305, 1999.

[9] X. Ge, J. Ren, Y. Pu, W. Ma, and Y. Zhu, "Real-in time CT test of the rock meso-damage propagation law," Science in China Series E: Technological Sciences, vol. 44, no. 3, pp. 328-336, 2001.

[10] K. Ueta, K. Tani, and T. Kato, "Computerized X-ray tomography analysis of three-dimensional fault geometries in basement-induced wrench faulting," Engineering Geology, vol. 56, no. 1, pp. 197-210, 2002.

[11] P. Bésuelle, G. Viggiani, N. Lenoir et al., "X-ray micro CT for studying strain localization in clay rocks under triaxial compression," Advances in X-Ray Tomography for Geomaterials, pp. 35-52, ISTE, London, UK, 2006.

[12] L. B. Wang, J. D. Frost, G. Z. Voyiadjis, and T. P. Harman, "Quantification of damage parameters using X-ray tomography images," Mechanics of Materials, vol. 35, no. 8, pp. 777-790, 2003.

[13] W. Tian, F. N. Dang, and Y. L. Xie, "Quantitative study on crack of meso-damage and fracture concrete based on CT technique," Sadhana-Academy Proceedings in Engineering Sciences, vol. 40, no. 2, pp. 263-276, 2015.

[14] S. G. Li, R. K. Huo, and B. Wang, "Experimental study on physicomechanical properties of sandstone under acidic environment," Advances in Civil Engineering, vol. 2018, Article ID 5784831, 15 pages, 2018.

[15] E. Fjar, R. M. Holt, A. M. Risnes, and P. Horsrud, Petroleum Related Rock Mechanics, Elsevier, Amsterdam, Netherlands, 2008.

[16] A. A. Al-Harthi, R. M. Al-Amri, and W. M. Shehata, "The porosity and engineering properties of vesicular basalt in Saudi Arabia," Engineering Geology, vol. 54, no. 3-4, pp. 313-220, 1999.

[17] Y. X. Li and J. Wang, "Effects of porosity of dry and saturated sandstone on the energy dissipation of stress wave," Advances in Civil Engineering, vol. 2019, Article ID 9183969, 10 pages, 2019.

[18] D. F. Howarth and J. C. Rowlands, "Quantitative assessment of rock texture and correlation with drillability and strength properties," Rock Mechanics and Rock Engineering, vol. 20, no. 1, pp. 57-85, 1987.

[19] A. Ersoy and M. D. Waller, "Textural characterization of rocks," Engineering Geology, vol. 39, no. 3-4, pp. 123-136, 1995.

[20] A. Azzoni, F. Bailo, E. Rondena, and A. Zaninetti, “Assessment of texture coefficient for different rock types and correlation with uniaxial compressive strength and rock weathering," Rock Mechanics and Rock Engineering, vol. 29, no. 1, pp. 39-46, 1996.

[21] M. Alber and S. Kahraman, "Predicting the uniaxial compressive strength and elastic modulus of a fault breccia from texture coefficient," Rock Mechanics and Rock Engineering, vol. 42, no. 1, pp. 117-127, 2009.

[22] R. S. Tandon and V. Gupta, "The control of mineral constituents and textural characteristics on the petrophysical \& mechanical (PM) properties of different rocks of the Himalaya," Engineering Geology, vol. 153, pp. 125-143, 2013.

[23] C. A. Ozturk and E. Nasuf, "Strength classification of rock material based on textural properties," Tunnelling and Underground Space Technology, vol. 37, pp. 45-54, 2013.

[24] S. Chen, Z. Q. Yue, and L. G. Tham, "Digital image based approach for three-dimensional mechanical analysis of heterogeneous rocks," Rock Mechanics and Rock Engineering, vol. 40, no. 2, pp. 145-168, 2007.
[25] W. C. Zhu, Y. M. Kang, T. H. Yang et al., "Application of digital image-based heterogeneity characterization in coupled hydromechanics of rock," Chinese Journal of Geotechnical Engineering, vol. 28, no. 12, pp. 2087-2091, 2006.

[26] Z. Q. Yang, S. H. Wang, Y. R. Meng et al., "Reconstruction model and application of three-dimensional numerical specimen based on CT scanning," Chinese Journal of Solid Mechanics, vol. 38, no. 6, pp. 591-600, 2017.

[27] J. B. Zhu, T. Zhou, Z. Y. Liao, L. Sun, X. B. Li, and R. Chen, "Replication of internal defects and investigation of mechanical and fracture behaviour of rock using $3 \mathrm{D}$ printing and 3D numerical methods in combination with X-ray computerized tomography," International Journal of Rock Mechanics and Mining Sciences, vol. 106, pp. 198-212, 2018.

[28] Y. Ju, H. Wang, Y. Yang, Q. Hu, and R. Peng, "Numerical simulation of mechanisms of deformation, failure and energy dissipation in porous rock media subjected to wave stresses," Science China Technological Sciences, vol. 53, no. 4, pp. 1098-1113, 2010.

[29] W. Tian, F. N. Dang, and H. Q. Chen, "Three-dimensional reconstruction of concrete CT images," Journal of Sichuan University (Engineering Science Edition), vol. 42, no. 6, pp. 12-16, 2010.

[30] J. B. Wang, Numerical simulation of three-dimensional reconstruction and microscopic seepage of rock pore structure, Ph.D. thesis, China University of Mining and Technology, Beijing, China, 2014.

[31] R. Song, J. Liu, and M. Cui, "A new method to reconstruct structured mesh model from micro-computed tomography images of porous media and its application," International Journal of Heat and Mass Transfer, vol. 109, pp. 705-715, 2017.

[32] R. Song, M. Cui, J. J. Liu, and P. G. Ranjith, Y. Lei, A porescale simulation on thermal-hydromechanical coupling mechanism of rock," Geofluids, vol. 2017, Article ID 7510527, 2017.

[33] Y. Wang, R. Song, J. J. Liu, and M.-M. Cui, P.G. Ranjith, Pore scale investigation on scaling-up micro-macro capillary number and wettability on trapping and mobilization of residual fluid," Journal of Contaminant Hydrology, vol. 225, Article ID 103499, , 2019.

[34] C. L. Wang, "Three-dimensional reconstruction model and numerical simulation of rock fissures," Evolution, Monitoring and Predicting Models of Rock Burst, Springer, Singapore, pp. 35-58, 2018.

[35] Z. L. Cheng, W. B. Sui, Z. F. Ning et al., "Study on microstructure characteristics of digital core and its influence on rock mechanical properties," Chinese Journal of Rock Mechanics and Engineering, vol. 2, no. 37, pp. 450-460, 2018.

[36] J. Liu, J. Sarout, M. Zhang, J. Dautriat, E. Veveakis, and K. Regenauer-Lieb, "Computational upscaling of DruckerPrager plasticity from micro-CT images of synthetic porous rock," Geophysical Journal International, vol. 212, no. 1, pp. 151-163, 2018.

[37] N. P. Daphalapurkar, F. Wang, B. Fu, H. Lu, and R. Komanduri, "Determination of mechanical properties of sand grains by nanoindentation," Experimental Mechanics, vol. 51, no. 5, pp. 719-728, 2010.

[38] J. M. Nevitt, J. M. Warren, and D. D. Pollard, "Testing constitutive equations for brittle-ductile deformation associated with faulting in granitic rock," Journal of Geophysical Research: Solid Earth, vol. 122, no. 8, pp. 6269-6293, 2017.

[39] X. Hu, X. Song, Y. Liu et al., "Lowest required surface temperature for thermal spallation in granite and sandstone 
specimens: experiments and simulations," Rock Mechanics and Rock Engineering, vol. 52, no. 6, pp. 1689-1703, 2019.

[40] N. S. Ottosen and M. Ristinmaa, The Mechanics of Constitutive Modeling, Elsevier, Amsterdam, Netherlands, 2005.

[41] C. E. Fairhurst and J. A. Hudson, "Uniaxial compression test for the complete rock stress-strain full curve ISRM recommended method," Chinese Journal of Rock Mechanics and Engineering, vol. 19, no. 6, pp. 802-808, 2000.

[42] Y. R. Liu and H. M. Tang, Rock Mass Mechanics, Chemical industry press, Beijing, China, 2008.

[43] Y. D. Lu, Research on triaxial compression test of rock and linear softening constitutive model, Ph.D. thesis, Shanghai Jiao Tong University, Shanghai, China, 2003.

[44] N. Epstein, "On tortuosity and the tortuosity factor in flow and diffusion through porous media," Chemical Engineering Science, vol. 44, no. 3, pp. 777-779, 1989.

[45] S. J. Cooper, A. Bertei, P. R. Shearing, J. A. Kilner, and N. P. Brandon, "TauFactor: an open-source application for calculating tortuosity factors from tomographic data," SoftwareX, vol. 5, pp. 203-210, 2016.

[46] S. Nemat-Nasser and M. Hori, Micromechanics: Overall Properties of Heterogeneous Materials, Elsevier, Amsterdam, Netherlands, 1993.

[47] W. Pabst, E. Gregorová, and M. Černý, "Isothermal and adiabatic Young's moduli of alumina and zirconia ceramics at elevated temperatures," Journal of the European Ceramic Society, vol. 33, no. 15-16, pp. 3085-3093, 2013.

[48] X.-P. Zhou and N. Xiao, "A novel 3D geometrical reconstruction model for porous rocks," Engineering Geology, vol. 228, no. 13, pp. 371-384, 2017.

[49] R. Přikryl, "Some microstructural aspects of strength variation in rocks," International Journal of Rock Mechanics and Mining Sciences, vol. 38, no. 5, pp. 671-682, 2001.

[50] H. S. Salem and G. V. Chilingarian, "Influence of porosity and direction of flow on tortuosity in unconsolidated porous media," Energy Sources, vol. 22, no. 3, pp. 207-213, 2010.

[51] R. Wang, T. Pavlin, M. S. Rosen, R. W. Mair, D. G. Cory, and R. L. Walsworth, "Xenon NMR measurements of permeability and tortuosity in reservoir rocks," Magnetic Resonance Imaging, vol. 23, no. 2, pp. 329-331, 2005.

[52] M. A. Attia, "Effects of petrophysical rock properties on tortuosity factor," Journal of Petroleum Science and Engineering, vol. 48, no. 3-4, pp. 185-198, 2005. 